\title{
Modulation of C. elegans Touch Sensitivity Is Integrated at Multiple Levels
}

\author{
Xiaoyin Chen (陈筱寅) and Martin Chalfie \\ Department of Biological Sciences, Columbia University, New York, New York 10027
}

Sensory systems can adapt to different environmental signals. Here we identify four conditions that modulate anterior touch sensitivity in Caenorhabditis elegans after several hours and demonstrate that such sensory modulation is integrated at multiple levels to produce a single output. Prolonged vibration involving integrin signaling directly sensitizes the touch receptor neurons (TRNs). In contrast, hypoxia, the dauer state, and high salt reduce touch sensitivity by preventing the release of long-range neuroregulators, including two insulin-like proteins. Integration of these latter inputs occurs at upstream neurohormonal cells and at the insulin signaling cascade within the TRNs. These signals and those from integrin signaling converge to modulate touch sensitivity by regulating AKT kinases and DAF-16/FOXO. Thus, activation of either the integrin or insulin pathways can compensate for defects in the other pathway. This modulatory system integrates conflicting signals from different modalities, and adapts touch sensitivity to both mechanical and nonmechanical conditions.

Key words: insulin signaling; integrin signaling; long-term sensitization; mechanosensation; sensory modulation

\section{Introduction}

Various conditions modulate sensory perception and can change behavioral responses to sensory stimuli. The human sense of smell, for example, is regulated by multiple hormones that reduce the olfactory attraction of food when individuals are not hungry (Palouzier-Paulignan et al., 2012). In addition the response of songbirds to songs depends on estradiol levels, which fluctuate seasonally (Maney and Pinaud, 2011), and gustatory chemosensation in the nematode Caenorhabditis elegans is enhanced during hypoxic conditions because additional neurons are recruited into the circuit (Pocock and Hobert, 2010). Sensory modulation can occur through direct synaptic connections (Fex, 1967), longrange neuropeptides (Palouzier-Paulignan et al., 2012), and hormones (Maney and Pinaud, 2011; Palouzier-Paulignan et al., 2012). Sensory cells can also self-modulate, e.g., the dynamic range of mammalian cone and rod cells changes in response to overall brightness (Fain et al., 2001).

Mechanosensation, in particular, can be modulated in multiple ways. Both hearing and touch sensitivity habituate to repeated

Received Jan. 3, 2014; revised March 11, 2014; accepted March 31, 2014.

Author contributions:X.C. and M.C. designed research; X.C. performed research; X.C. and M.C. analyzed data; X.C. and M.C. wrote the paper.

This work was supported by grant GM30997 to M.C. from the National Institutes of Health (NIH). The authors declare no competing financial interests. We thank the Caenorhabditis Genetics Center, which is funded by NIH Office of Research Infrastructure Programs (P40 0D010440); the International C. elegans Gene Knockout Consortium; and the Japan National Bioresource Project for the Nematode C. elegans for providing most of the strains. We thank Alexander Gottschalk for the mec-4p::chr2::yfp plasmid; Irini Topalidou and Nicola Mandriota for generating the TU\#929 and the TU\#1115 plasmids; Chaogu Zheng for generating the TU4523 strain; and Joy Alcedo, Jeff Lichtman, Charles Liberman, Ranulfo Romo, Ellen Lumpkin, Itamar Glazer, and the members of our lab for discussions.

Correspondence should be addressed to Martin Chalfie, Department of Biological Sciences, 1012 Fairchild, MC\#2446, Columbia University, 1212 Amsterdam Avenue, New York, NY 10027. E-mail: mc21@columbia.edu.

DOI:10.1523/JNEUROSCI.0022-14.2014

Copyright $\odot 2014$ the authors $\quad 0270-6474 / 14 / 346522-15 \$ 15.00 / 0$ stimuli (Pinsker et al., 1970; Weber, 1970), and touch sensitivity sensitizes when it is paired with a second obnoxious stimulus (Pinsker et al., 1973). Both mechanosensory habituation and sensitization have been attributed to synaptic plasticity. A less studied form of sensitization, produced by sustained normal stimulation, affects mammalian hearing and touch (Kujawa and Liberman, 1999; Govindaraju et al., 2006). In addition, visual and auditory inputs can modify mechanosensory perception in humans (Hötting et al., 2003; Longo et al., 2011) and motor function modulates the sensation of stretch in crustaceans (Sillar and Skorupski, 1986). How multiple and conflicting signals integrate to modulate mechanosensation, however, is unclear.

In C. elegans, gentle touch is sensed by six touch receptor neurons (TRNs), which detect changes in applied force and adapt quickly to constant pressure (O'Hagan et al., 2005). Transduction occurs through the MEC-4 DEG/ENaC channel complex (O'Hagan et al., 2005). The TRN touch response habituates to repeated stimuli given over several minutes and sensitizes for a short time ( $\sim 2 \mathrm{~min}$ ) following a single strong stimulus (Rankin et al., 1990).

In this paper, we show that $C$. elegans mechanosensation is sensitized by sustained vibration or tapping and reduced under several stress conditions (high salt, low oxygen, or the dauer state). Unlike previously reported habituation and short-term sensitization (Rankin et al., 1990), however, the changes we report here occur on a longer timescale (hours rather than minutes) and only affect the anterior TRNs. These conditions signal through three different sets of neurons and two molecular pathways and integrate at multiple points along these pathways. We further demonstrate the behavioral and adaptive consequences of such modulation. 
Table 1. C. elegans strain list

\begin{tabular}{|c|c|c|}
\hline & Genotype & Comments \\
\hline N2 & + & Wild-type \\
\hline TU3842 & uls109 (pCW2.1, mec-17p::.gcamp3) IIl; him-5(e1490) V & Control GCaMP3 strain \\
\hline TU3851 & uls91 (mec-4p:::ChR2::yfp, pCFJ104) III; sid-1(pk3321) him-5(e1490) V & ChR2 strains, for crosses \\
\hline TU3849 & uls94 (mec-4p::ChR2::yfp, p(FJ104); sid-1(pk3321) him-5(e1490) V & \\
\hline TU4274 & uls156 (unc-112p::unc-112::gfp) & \\
\hline TU4382 & uEx885 (pat-2p:::gfp, p(FJ90) & \\
\hline TU3836 & pat-2(ok2148); uEx829( pat-2p::pat-2, p(FJ90, mec-3p:::rfp) & Rescued focal adhesion mutants for mosaic analyses \\
\hline TU3837 & pat-2(ok2148); uEx830(pat-2p:::pat-2, p(FJ90, mec-3p:::rfp) & \\
\hline TU3689 & pat-3(st564); uEx826(pat-3p::pat-3, p(FJ90, mec-3p:::fp) & \\
\hline TU3834 & pat-6(st561); uEx827(pat-6p::pat-6, p(FJ90, mec-3p::rfp) & \\
\hline TU3687 & unc-112( gk1); uEx824(unc-112p::unc-112, p(FJ90, mec-3p::rfp) & \\
\hline TU3839 & unc-97(ra115)dpy-8(e130); uEx832(unc-97p::unc-97, p(FJ90, mec-3p::rfp) & \\
\hline TU4365 & uls91 (mec-4p:::ChR2::yfp, p(FJ104) III & Control ChR2 strain \\
\hline TU3850 & pat-2(ok2148) III; uls94; uEx830 & TRN::ChR2 in focal adhesion mutants and egl- 19 \\
\hline TU3859 & pat-3(st564) III; uls94; uEx826 & made by crossing TU3849 or TU3851 into each \\
\hline TU3853 & uls91 III; pat-6(st561) IV; uEx827 & rescued strain and egl-19 \\
\hline TU3854 & uls91 III; unc-97(ra115)dpy-8(e130) X; uEx832 & \\
\hline TU3852 & uls91 III; unc-112( gk1) V; uEx824 & \\
\hline TU3855 & uls91 III; egl-19(ad1013) IV; sid-1(pk3321) him-5(e1490) V & \\
\hline NG155 & ina-1( gm144) III & \\
\hline NG39 & ina-1( gm39) III & \\
\hline TU4275 & uls109 IIl; egl-19(ad1006) IV & GCaMP3 in egl-19 \\
\hline TU3844 & pat-2(ok2148) uls109 III; uEx829 & GCaMP3 in pat-2 \\
\hline TU4277 & uls109 III; unc-112( gk1); uEx862 (unc-112p::unc-112, p(FJ90, mec-3p::rfp) & GCaMP3 in unc-112 \\
\hline JT9609 & $p d k-1(s a 680) X$ & \\
\hline RB759 & akt-1(ok525) V & \\
\hline VC204 & akt-2(ok393)X & \\
\hline TU4423 & akt-1 (ok525) V; akt-2(ok393)X & Maintained on daf-16 RNAi \\
\hline TU4383 & pdk-1(sa680) X; uEx874 (mec-17p::unc-112::gfp, mec-17p::pat-6::gfp, p(FJ90, mec-17p::gfp) & TRN::unc-112/pat-6 overexpression \\
\hline TU4384 & akt-1(ok525) V; uEx874 & \\
\hline CB1370 & daf-2(e1370) III & \\
\hline TU4276 & akt-1(mg144) unc-112( gk1) V; uEx862 (unc-112p::unc-112, p(FJ90, mec-3p::rfp) & akt-1gfunc-112 \\
\hline TU4279 & daf-16(mgDf50) l; unc-112( gk1) V; uEx862 (unc-112p:::unc-112, p(FJ90, mec-3p::rfp) & daf-16; unc-112 \\
\hline TU4280 & pat-2(ok2148) uls109 III; akt-1 (mg144); uEx829 & akt-1gf; pat-2 \\
\hline GR1310 & akt-1(mg144) V & \\
\hline RB1679 & cav-1(ok2089) IV & \\
\hline TU45 & $\operatorname{mec}-4(u 45) X$ & mec- 4 ts allele \\
\hline TU4282 & akt-1(mg144) V; mec-4(u45)X & \\
\hline TU4283 & daf-16(mgDf50) l; mec-4(u45)X & \\
\hline TU4385 & mec-4(u45) X;uEx874 & mec-4ts + TRN::unc-112/pat-6 \\
\hline GR1307 & daf-16(mgDf50) I & \\
\hline TU4289 & him-4(e1267) uls157 (mec-3p::pdk-1gf, p(FJ90, mec-3p:::rfp)X & TRN::pdk-1gf in him-4 \\
\hline TU3595 & sid-1(pk3321) him-5(e1490) V; lin-15B(n744) X; uls72 & Neuronally enhanced RNAi (Calixto et al., 2010) \\
\hline CB1267 & $\operatorname{him}-4(e 1267) X$ & \\
\hline JK1438 & daf-2(m65)/q(1 dpy-19(e1259) g/p-1(q339) III & \\
\hline CY401 & sqt-1(sc13) age-1(mg109)/mnC1 dpy-10(e128) unc-52(e444) II & \\
\hline RB712 & daf-18(ok480) IV & \\
\hline GR1318 & $p d k-1(m g 142) X$ & pdk-1 gain-of-function allele \\
\hline DR1942 & daf-2(e979) III & \\
\hline DR1564 & daf-2(m41) III & \\
\hline PJ1146 & daf-2(m41) III; ccls55 V;pdk-1(mg142)X & \\
\hline HТ1890 & daf-16(mgDf50) I; daf-2(e1370) III & \\
\hline DR1309 & daf-16(m26) I; daf-2(e1370) II & \\
\hline TU4371 & $\begin{array}{l}\text { daf-2(m65)/qC1 dpy-19(e1259) glp-1(q339) III; uEx874(mec-17p::unc-112::gfp, mec-17p::pat-6::gfp, } \\
\quad \text { (FJ90, mec-17p::gfp) }\end{array}$ & overexpresses TRN::unc-112/pat-6 in daf-2 \\
\hline TU4372 & $\begin{array}{l}\text { daf-2(m65)/qC1 dpy-19(e1259) glp-1(q339) III; uEx875(mec-17p::unc-112::gfp, mec-17p::pat-6::gfp, } \\
\quad \text { p(FJ90, mec-17p:::ffp) }\end{array}$ & overexpresses TRN::unc-112/pat-6 in daf-2 \\
\hline TU4278 & unc-112( gk1) V;pdk-1(mg142) X; uEx862 & unc-112; pdk-1gf \\
\hline TU4281 & pat-2(ok2148) uls109 III; pdk-1(mg142); uEx829 & pat-2; pdk-1gf \\
\hline $\mathrm{FX} 2988^{a}$ & ins-33(tm2988) I & \\
\hline TU3927 & uls126 (ins-10p::ins-10(i), ins-10p::rfp, pCW2.1) & ins-10(i) strain \\
\hline TU3929 & uls128 (ins-10p::ins-10(i), ins-10p::rfp, pCW2.1) & ins-10(i) strain \\
\hline TU4373 & uls128; uEx880 (ins-10p::ins-10rec, p(FJ90, ins-10p:::gfp) & ins- 10 with alternative codons rescuing ins-10(i) \\
\hline
\end{tabular}


Table 1. Continued

\begin{tabular}{|c|c|c|}
\hline & Genotype & Comments \\
\hline TU4374 ${ }^{a}$ & ins-10(tm3498) V; uEx876 (ins-10p::ins-10(+), p(FJ90, ins-10p::gfp) & ins- $10(+)$ rescuing ins-10(tm3498) \\
\hline FX4990 & ins-22(tm4990) III & \\
\hline${\text { TU } 4375^{a}}^{a}$ & ins-22(tm4990) III; uEx877 (ins-22(+), pCFJ90, ins-22p::gfp) & ins-22 rescue \\
\hline TU4368 & uls128; rde-1(ne219) V & ins-10(i) with rde-1 \\
\hline TU4290 & uls109 III; uls126 & GCaMP3 in ins-10(i) \\
\hline TU4291 & uls109 III; uls128 & GCaMP3 in ins-10(i) \\
\hline TU4292 & akt-1(mg144) V; uls128 & ins-10(i); akt-1gf \\
\hline TU4293 & $p d k-1(m g 142) X ; u l s 128$ & ins-10(i);pdk-1gf \\
\hline TU4294 & uls157 (mec-3p:::pdk-1gf, p(FJ90, mec-3p:::Ifp) X; uls 128 & ins-10(i); TRN:.:pdk-1gf \\
\hline TU4376 & uls128; uEx880(mec-17p::unc-112::gfp, mec-17p::pat-6::gfp, p(FJ90, mec-17p::gfp) & ins-10(i) + TRN::unc-112/pat-6 \\
\hline TU4377 & uls128; uEx881(mec-17p::unc-112:::gfp, mec-17p::pat-6::gfp, p(FJ90, mec-17p::gfp) & ins-10(i) + TRN::unc-112/pat-6 \\
\hline TU4378 & uEx878 (ins-10p:::gfp, p(FJ90) & \\
\hline TU4379 & uEx879 (ins-10p::rfp, pCW2.1) & \\
\hline TU4296 & uls157 (mec-3p::pdk-1gf, p(FJ90, mec-3p:::rfp) X & \\
\hline TU4369 & uls162 (ins-22p::gfp, pCFJ104) & ins-22p::gfp \\
\hline $\mathrm{OH} 3679$ & che-1(ot151) otls114I & \\
\hline TU4297 & che-1(ot151) otls114l; uls157 (mec-3p::pdk-1gf, pCFJ90, mec-3p:::fp) X & che-1; TRN::pdk-1gf \\
\hline TU4380 & uEx874(mec-17p::unc-112::gfp, mec-17p::pat-6::gfp, p(FJ90, mec-17p:::gfp) & Wild type overexpressing TRN:::unc-112/pat-6 \\
\hline TU4381 & uEx875(mec-17p::unc-112::gfp, mec-17p::pat-6::gfp, p(FJ90, mec-17p:::fp) & Wild type overexpressing TRN::unc-112/pat-6 \\
\hline $\mathrm{RB} 2059^{b}$ & ins-28(ok2722) & \\
\hline TU4295 & uls152(mec-3p::rfp) & mec-3p:::rfp \\
\hline TU4473 & akt-1(ok525) V; uEx891(mec-17p:::gfp, mec-17p::akt-1a, pCFJ90) & mec-17p::akt-1a rescue \\
\hline TU4474 & akt-1(ok525) V; uEx892(mec-17p::gfp, mec-17p::akt-1a, p(FJ90) & mec-17p::akt-1a rescue \\
\hline TU4475 & akt-1(ok525) V; uEx893(mec-17p::gfp, mec-17p::akt-1a, pCFJ90) & mec-17p::akt-1a rescue \\
\hline TU4476 & daf-16 (mgDf50) l; uEx894(mec-17p:::gfp, mec-3p:::daf-16a, p(FJ90) & mec-17p:::daf-16a rescue \\
\hline TU4477 & daf-16 (mgDf50) l; uEx895(mec-17p:::gfp, mec-3p::daf-16a, p(FJ90) & mec-17p::daf-16a rescue \\
\hline TU4478 & daf-16 (mgDf50) l; uEx896(mec-17p::gfp, mec-3p::daf-16a, p(FJ90) & mec-17p:::daf-16a rescue \\
\hline TU4479 & daf-16 (mgDf50) I; uEx897(mec-17p::gfp, mec-3p::daf-16b, pCFJ90) & mec-17p::daf-16b rescue \\
\hline TU4480 & daf-16 (mgDf50) l; uEx898(mec-17p:::gfp, mec-3p::daf-16b, pCFJ90) & mec-17p::daf-16b rescue \\
\hline TU4481 & daf-16 (mgDf50) l; uEx899(mec-17p::gfp, mec-3p::daf-16b, p(FJ90) & mec-17p::daf-16b rescue \\
\hline TU4523 & uls113(mec-3p::gcamp3, mec-3p::rfp) V;uls135 & GCaMP3 in interneurons \\
\hline TU4521 & uls113 V; uls135; mec-4(u253)X & mec- 4 control for GCaMP3 in interneurons \\
\hline
\end{tabular}

${ }^{a}$ All tm alleles were obtained from the Japan National Bioresource Project for the nematode C. elegans. ${ }^{b}$ RB2059, carrying ins-28(ok2722), was initially touch insensitive, but animals responded to touch after outcrossing, suggesting that the touch insensitivity was a background effect. ChR2, channelrhodopsin-2.

\section{Materials and Methods}

Strains and treatments. C. elegans strains (Table 1) were maintained at $15^{\circ} \mathrm{C}$ or $20^{\circ} \mathrm{C}$ as described previously (Brenner, 1974). Hermaphrodites were used for all experiments. Temperature-sensitive strains were maintained at $15^{\circ} \mathrm{C}$ and transferred to $25^{\circ} \mathrm{C}$ for one generation before testing. Most of the strains came from the Caenorhabditis Genetics Center, which is funded by NIH Office of Research Infrastructure Programs (P40 OD010440). pat-2(ok2148) III, unc-112( gk1) V, akt-1(ok525) V, and akt2(ok393) $X$ were generated by the International C. elegans Gene Knockout Consortium (http://www.celeganskoconsortium.omrf.org).

To study the importance of insulin-like peptides, we examined the effects of mutant alleles for all ins genes except for ins-19, ins-20, ins-21, ins-24, ins-32, ins-36, and ins-39, which we tested using feeding RNAi. Because the putative deletion allele, ins-10(tm3498), produced detectable ins-10 mRNA (J. Alcedo, personal communication; data not shown), we used animals carrying a construct expressing an ins-10 hairpin from the ins-10 promoter to induce RNAi against ins-10 [ins-10(i)].

The hypoxic treatment was performed as described previously (Pocock and Hobert, 2010).

Dauers were obtained by growing mixed-stage animals at $25^{\circ} \mathrm{C}$ until they depleted the bacteria on the plate (usually after one generation) and then further starved for $5 \mathrm{~d}$. The dauer animals were then either tested for touch sensitivity directly, or separated from non-dauer animals by $1 \%$ SDS treatment for $30 \mathrm{~min}$ for the chemotaxis assay. Because dauers were obtained by starvation, all assays involving them used starved L3 larvae as controls.

For high-salt treatments, the animals were grown for one generation on NGM plates (Brenner, 1974) supplemented with an additional 180 $\mathrm{mm} \mathrm{NaCl}$ to produce a final $\mathrm{NaCl}$ concentration of $230 \mathrm{~mm}$. For amiloride treatment, bus-17 animals, which are more permeable to drugs as adults (Gravato-Nobre et al., 2005; Bounoutas et al., 2009), were transferred to $230 \mathrm{~mm} \mathrm{NaCl}$ plates supplemented with $2 \mathrm{~mm}$ amiloride hydrochloride hydrate (Sigma-Aldrich) for at least $2 \mathrm{~h}$, vibrated for $2 \mathrm{~h}$, and recovered for $1 \mathrm{~h}$ on $230 \mathrm{~mm} \mathrm{NaCl}$ plates without amiloride before testing. For channelrhodopsin-2 activation during culture, TU3851 animals were grown on $230 \mathrm{~mm} \mathrm{NaCl}$ plates supplemented with $500 \mu \mathrm{M}$ all transretinal (Sigma-Aldrich) until the L4 stage, wrapped in aluminum foil, and illuminated by an LXML-PB01-0040 Luxeon Rebel $470 \mathrm{~nm}$ LED (Philips Lighting) at $3.4 \mathrm{~V}$ and $700 \mathrm{~mA}$ continuously for $2 \mathrm{~h}$, then rested for 30-40 min before testing.

For all vibrations, we played .wav files containing the appropriate waveforms through 3.5" (for culture) or 5.25" (for observation) dual cone speakers amplified by a digital amplifier. The outer cone of the speaker was removed, leaving only the inner cone as a stand for the plates. A lid of a $3.5 \mathrm{~cm}$ Petri dish (BD Falcon 351008) was glued to the top of the cone facing up, and the bottom of the dish was glued to a test plate, also facing up. The test plate was then put on the speaker by fitting the dish bottom to the lid, which produced enough friction to hold the plate in place. The .wav files were written with MATLAB (MathWorks). The average acceleration of the vibration was quantified using a DEACCM6G accelerometer (Dimension Engineering) on top of the plates. To observe the plates under vibration, we illuminated the plates on one side from underneath and recorded at a resolution of $1920 \times 1080$ with a Canon EOS 60D camera (Canon USA) with an Olympus OM $50 \mathrm{~mm} f / 2$ Macro lens (Olympus Imaging America).

For prolonged vibration, the animals were vibrated with $50 \mathrm{~Hz}$ square waves for $24 \mathrm{~h}$ with an average acceleration of $1.5 \times \mathrm{g}$, and recovered from habituation for 30-40 min before testing except for calcium imaging experiments and the habituation recovery assay, in which the animals were tested after resting for times indicated in the following sections. 
Constructs. The full list of primers and plasmids used is available upon request. Most constructs were made using the three-fragment Gateway system (Life Technologies) according to the manufacturer's instructions using the pDONRP4-P1r, pDONR221, pDONRP2r-P3, and pDESTR4-R3 vectors unless noted otherwise.

Behavioral assays. All behavioral assays were performed blind with regard to genotype. At least three biologically independent tests were performed for each strain. For mosaic analyses and laser ablations, the average and SEM of the response of animals were reported. For vibration-induced behaviors, the number of animals from independent tests were summed together and reported. For all other tests, the average and SEM of the means from the independent tests were reported.

The touch response was assayed by gently touching the side of the animal (see below for validations). Each animal was tested five times anteriorly and five times posteriorly unless noted (Hobert et al., 1999). Ten to 20 animals were tested each time, and each strain was tested at least three times independently.

To test activation by channelrhodopsin-2 (Nagel et al., 2005), bleached eggs were put on plates seeded with $100 \mu \mathrm{l}$ Escherichia coli OP50 in LB broth at the stationary phase $\left(\mathrm{OD}_{595}=0.45\right.$; Brenner, 1974) with $500 \mu \mathrm{M}$ all trans-retinal (Sigma-Aldrich). Animals grown for $5 \mathrm{~d}$ at $15^{\circ} \mathrm{C}$ were tested as young adults under a Leica M12 stereoscope modified with a M2 Bio Quad fluorescent attachment (Kramer Scientific) and an EXFO $\mathrm{X}$-cite 120 metal halide light source (EXFO). We then exposed each worm to a $<0.5 \mathrm{~s}$ flash of blue light coming from the GFP filter under a $20 \times \mathrm{f}=0.6$ objective and $12 \times$ zoom aimed at the ALM cell body. A fast backward movement within the $0.5 \mathrm{~s}$ exposure was counted as a positive response. Each animal was tested three times instead of five times because considerable habituation occurs after three tests (Nagel et al., 2005). The vibration response assays (Fig. 10A) were performed using $50 \mathrm{~Hz}, 0.5 \mathrm{~s}$ square pulses with an average plate acceleration of $1.7 \times \mathrm{g}$. Each plate was tested twice with at least $10 \mathrm{~min}$ in between, and the data from independent plates were pooled for analysis.

To test the response to nonlocalized vibration, animals were stimulated with a $0.5 \mathrm{~s} 0 \mathrm{~dB} 50 \mathrm{~Hz}$ square wave pulse vibration reaching an average acceleration of $1.7 \times \mathrm{g}$. We videotaped the experiments and then counted the number of animals that backed within $0.5 \mathrm{~s}$ of the stimulus on the video and measured the turning angle of the animals that backed. The animals that did not back were given a turning angle of $0^{\circ}$ and the average turning angle was calculated for all animals.

To test touch sensitivity during background vibration (Fig. 10D), we inserted a $0.5 \mathrm{~s}, 0 \mathrm{~dB} 50 \mathrm{~Hz}$ square wave pulse in a background of $-4 \mathrm{~dB}$ $50 \mathrm{~Hz}$ square wave vibration, reaching average accelerations of 1.7 and $0.7 \times g$ in the plates, respectively. We videotaped the animals and counted the number of animals that backed within $0.5 \mathrm{~s}$ of the stimulus on the videos.

To test recovery from habituation (Fig. $10 E, F$ ), we tested animals at various times after cessation of vibration with a sustained $50 \mathrm{~Hz}$ square wave with an average acceleration of $1 \times g$. Responses of animals were pooled from multiple plates.

The chemotaxis assay with tapping was performed using a mechanical tapper driven by a magnetic relay as described previously (Rankin et al., 1990). Animals were then allowed to move toward a spot of diacetyl for a fixed amount of time. The ratio of the chemotaxis efficiency index (CEI; percentage of animals that had reached the spot) with or without tapping was then calculated, and the means and SEMs of the ratios were reported.

Touch test validation. Originally, the touch assay was done by stroking a thin hair (eyebrow hair) across the animal (Chalfie and Sulston, 1981). However, by only touching the side of the animal, we were able to detect more subtle changes in touch sensitivity. For akt-1(ok525) animals, five anterior touches produced on average $4.4 \pm 0.2$ responses (mean \pm SEM of responses of individual animals, $n=20$ ) by stroking a thin hair across the animal, and $1.7 \pm 0.2(n=19)$ by touching the side of the animal. Both methods produced similar scores for wild-type animals (4.9 \pm 0.1 for the original method and $4.6 \pm 0.1$ for side touch, $n=16$ and $n=18$, respectively).

Feeding RNAi. Feeding RNAi was performed as described previously (Calixto et al., 2010). All RNAi bacteria used were from the Ahringer
Table 2. Integrin signaling genes affecting mechanosensation

\begin{tabular}{|c|c|}
\hline \multicolumn{2}{|c|}{ Focal adhesion components } \\
\hline unc- $112^{a}$ & Mig-2 like \\
\hline pat- $2^{a}$ & $\alpha$-Integrin \\
\hline unc $-97^{a}$ & PINCH \\
\hline pat $-4^{a}$ & ILK \\
\hline$p x \mid-1$ & Paxillin \\
\hline pat- $\sigma^{a}$ & Actopaxin \\
\hline$n c k-1$ & NCK adapter protein 2 \\
\hline$Y 71 G 12 B 0.11^{a}$ & Talin \\
\hline $\operatorname{tag}-224$ & Ortholog of LMCD1 and TESTIN \\
\hline \multicolumn{2}{|l|}{ Rho GTPase related } \\
\hline $\operatorname{rga}-5$ & RHO-GTPase activating protein \\
\hline let-502 & Rho-binding ser/thr kinase ortholog (ROCK) \\
\hline unc-103 & ERG-like K + channel, activated by rho \\
\hline unc- 73 & Rho-GEF for ced-10, mig-2, rho-1 \\
\hline ced-2 & $\mathrm{SH} 2 / 3$ adapter protein \\
\hline pkc-1 & Ortholog to protein kinase $C \epsilon$ \\
\hline Y106G6HO.14 & Homolog of Yeast BEM1, which binds Cdc24p \\
\hline \multicolumn{2}{|c|}{ Insulin signaling pathway } \\
\hline daf-2 & Insulin receptor \\
\hline age-1 & PI3k p110 catalytic subunit \\
\hline$p d k-1$ & 3-Phosphoinositide-dependent kinase 1 ortholog \\
\hline \multicolumn{2}{|c|}{ Ras/MAP kinase pathway } \\
\hline $\operatorname{arf}-1.1$ & ADP-ribosylation factor, Ras superfamily GTPase \\
\hline let -60 & K-RAS \\
\hline$m p k-1$ & MAPK \\
\hline let-92 & PP2A catalytic subunit \\
\hline sos-1 & Son of sevenless, RAS-GEF \\
\hline \multicolumn{2}{|l|}{ Cytoskeleton } \\
\hline F42H10.3 & Yeast homolog binds Arp $2 / 3$ \\
\hline tba-1 & $\alpha$-Tubulin \\
\hline tsp-8 & Ortholog of KANGAI 1 \\
\hline
\end{tabular}

Twenty-nine of 87 conserved integrin signal genes (Zaidel-Bar, 2009) affected touch sensitivity through feeding RNAi. Two of the candidates, cav- 1 and daf-18, were subsequently identified as false positives. The remaining genes are listed here each followed by a concise description. ${ }^{a}$ Genes known to affect touch sensitivity (Calixto et al., 2010) and were included as positive controls.

library (Source Bioscience) except for ins-20 and ins-36, which were made in L4440 as described. Except for the feeding RNAi screen, we examined at least three independent plates at the same time.

For the feeding RNAi screen, we scored genes that caused touch insensitivity in three of four tests as positive. As a control we included the seven dense body genes found in our initial study (Calixto et al., 2010) in our list of 87 candidate genes, and we were able to identify six of them blindly (the remaining gene, pat-3, produced lethality in TU3595). RNAi for 23 of the remaining 80 genes reduced touch insensitivity (Table 2). Based on known functions or homology, the 23 genes included additional focal adhesion genes, genes in the Ras/MAPK pathway, insulin signaling pathway, Rho-GTPase-related genes, and cytoskeleton related genes. unc-73, which encodes a guanine exchange factor for several Rho-GTPases, and mec-12, which is a secondary target for $t b a-1$ RNAi, were previously reported to affect TRN functions and/or development (Hedgecock et al., 1987; Chalfie and Thomson, 1982).

For a single test, we estimated the false positive rate to be $<20 \%$ from a larger screen for $\sim 1000$ genes. Therefore, the false positive rate of the screen was estimated to be $C_{4}^{1} \times 0.2^{3} \times 0.8+0.2^{4}=2.7 \%$, corresponding to $2.7 \% \times 80=2$ false positives out of the 23 genes obtained from the screen ( 7 genes from the list of 87 genes did not have RNAi bacteria, and were not tested). Subsequent tests of all identified insulin and Ras/MAPK pathway genes using mutant alleles identified cav-1 and daf-18 as false positives in these two pathways.

Mosaic analysis. All tests on focal adhesion mutants were done on mosaic animals, except for RNAi treatments as indicated. Rescued pat-2, pat-3, pat-6, unc-97, and unc-112 strains all have mec-3p::rfp in the extrachromosomal rescuing array as a TRN marker. Animals were grown to the L4 stage and observed under a Leica M12 stereoscope modified with a M2 Bio Quad fluorescent attachment (Kramer Scientific) and an EXFO X-cite 120 metal halide light source. Animals lacking RFP in ALM and 
AVM cells, the two PLM cells, or having RFP in all six TRNs (controls) were selected and scored blindly for both anterior and posterior touch sensitivity. The anterior touch response of animals that had lost the rescuing array in the anterior TRNs and the posterior touch response of animals that had lost the rescuing array in the posterior TRNs were compared with both the anterior and posterior touch response of the controls. For calcium imaging experiments, the absence of RFP in the ALM cells was additionally confirmed under a $40 \times 0.95$ lens. For all experiments involving mosaic animals, at least two independent tests were done with the data pooled for analysis.

Laser ablations. Laser ablations were performed as described previously (Tsalik and Hobert, 2003). The M4 and I5 cells were labeled with GFP and ablated in L4 larvae. All animals were anesthetized with $30 \mathrm{~mm}$ sodium azide. Control animals were left in sodium azide on a slide for the same time as ablated animals, and mock-ablated animals had adjacent pharyngeal neurons ablated instead of M4 and I5. After $24 \mathrm{~h}$, the ablation was confirmed by the lack of GFP recovery in the M4 and I5 cells. The confirmed animals were then tested for touch sensitivity in blind tests. Ablating the M4 neuron prevented feeding, so the ablated animals were compared with mock ablated animals that were starved for $24 \mathrm{~h}$.

Calcium imaging. Calcium imaging was performed as described previously (Suzuki et al., 2003) using GCaMP3 with minor modifications on a Zeiss Observer Z1 microscope with a Photometrics Evolve 512 camera (Photometrics). Each animal was glued on its ventral surface using Dermabond (Ethicon) to a $4 \%$ agarose pad in M9 buffer on a $24 \times 60 \mathrm{~mm}$ No. 1 coverslip and covered with $100 \mu \mathrm{l}$ M9 buffer. We mounted the coverslip on a rotating stage on a Zeiss Observer Z1 microscope equipped with an Eppendorf TransferMan NK2 micromanipulator (Eppendorf North America). A glass probe with a round tip with a diameter of $22 \mu \mathrm{m}$ driven by a two-layer piezoelectric rectangular bending actuator (Piezo Systems) was mounted on the micromanipulator, and carefully placed next to the animal without pressing it and parallel to the animal. The piezo lever was driven by $250 \mathrm{~ms}$ square waves from a 33221A waveform generator (Agilent Technologies) through a Piezo Linear Amplifier (Piezo Systems). The square waves cause the probe to bend sideways in the $x-y$ plane, thus pressing the animal. During the recording, we illuminated the animal with a $470 \mathrm{~nm}$ LED from Colibri 2 (Carl Zeiss Microscopy) at 10\% intensity through a GFP filter cube, and recorded the images through a Zeiss Apochromat $40 \times 0.95$ lens with a Photometrics Evolve 512 camera at $\sim 10$ fps and analyzed with AxioVision (Carl Zeiss Microscopy).

Only late L4 larvae or young adult animals were used for calcium imaging in the TRNs, although L3 larvae had similar touch sensitivity and calcium response (data not shown). In a typical experiment, we touched an animal with a piezo probe and varied the stimulus by increasing the voltage from 0.01 to $1.6 \mathrm{~V}$, once or twice at each voltage, and recorded the calcium signal. Each stimulus was given when calcium re-

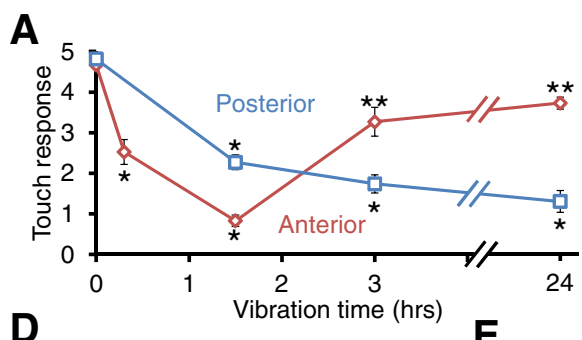

B

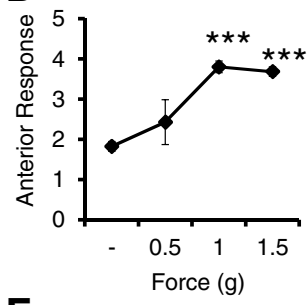

\begin{tabular}{|l|l|c|l|}
\hline & $\mathrm{D}_{50}(\mu \mathrm{m})$ & $\mathrm{k}$ & $\mathrm{n}$ \\
\hline ALM & $1.1 \pm 0.1$ & $3.3 \pm 0.3$ & 26 \\
\hline ALM(vib) & $0.6 \pm 0.2$ & $4.3 \pm 1.7$ & 7 \\
\hline $\begin{array}{l}\text { ALM } \\
\text { (recovery) }\end{array}$ & $1.5 \pm 0.3$ & $3.2 \pm 0.7$ & 6 \\
\hline PLM & $2.1 \pm 0.2$ & $1.9 \pm 0.5$ & 11 \\
\hline PLM(vib) & $2.2 \pm 0.3$ & $1.3 \pm 0.2$ & 6 \\
\hline
\end{tabular}

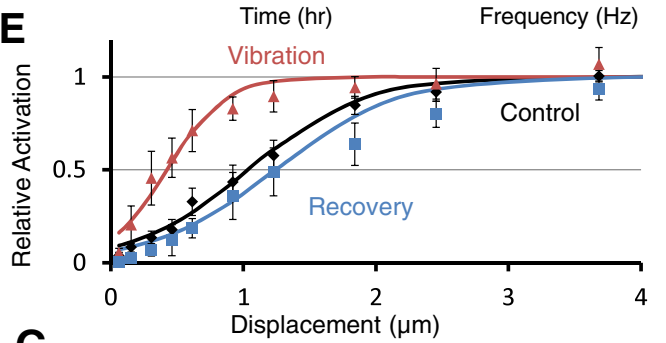

G

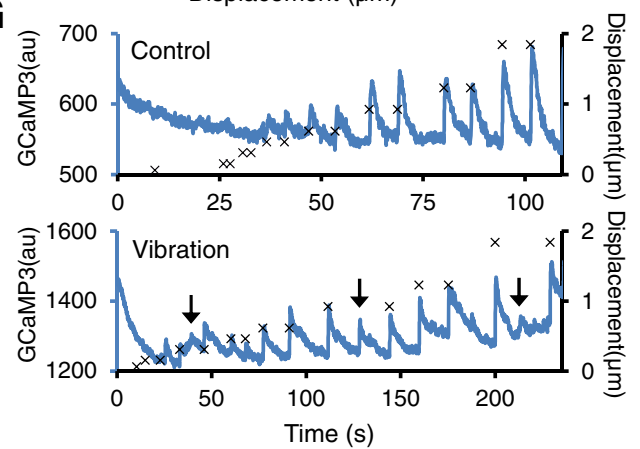

H
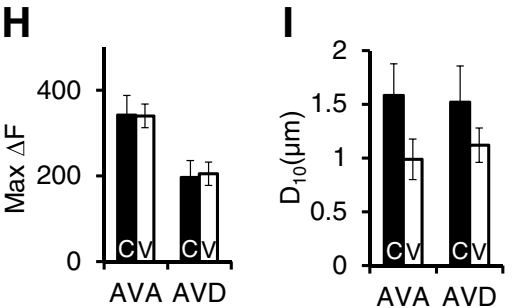

$\mathbf{J}$

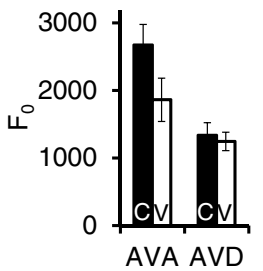

K

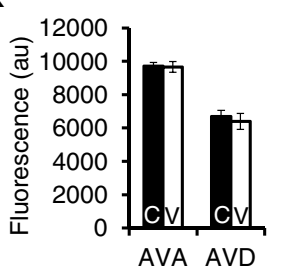

Figure 1. Sensitization to touch by vibration. $\boldsymbol{A}$, Anterior (red) and posterior (blue) response (mean \pm SEM) of wild-type to touch after sustained vibration for the indicated time. $P<0.005$ comparing responses with $0 \mathrm{~h}\left({ }^{*}\right)$ or $1.5 \mathrm{~h}\left({ }^{* *}\right) . N \geq 3$ for each time point. For all figures, $N$ represents the number of independent sets of animals tested, each with at least 10 animals, and $n$ represents the number of animals. $\boldsymbol{B}-\boldsymbol{D}$, Anterior touch sensitivity (mean $\pm \mathrm{SEM}$ ) in animals vibrated at various frequencies, strengths, and times. The enhancement of touch sensitivity by prolonged vibration was greatest when animals were $(\boldsymbol{B})$ vibrated for more than $2 \mathrm{~h}$ at $(\boldsymbol{C})$ a frequency of $50 \mathrm{~Hz}$ with $(\boldsymbol{D})$ an average acceleration $>1 \times g$. Values for anterior sensitivity are given as mean \pm SEM. The data for no vibration ( - ) and $2 \mathrm{~h}, 50 \mathrm{~Hz}, 1.5 \times g$ vibration from all the experiments were pooled and used for all three figures. Optima of the other parameters were used when testing a particular parameter; ${ }^{*} p<0.02,{ }^{* *} p<0.005$, ${ }^{* * *} p<$ $0.001, N \geq 3$ for all conditions tested. $\boldsymbol{E}$, Normalized calcium responses of control (black), vibrated (red) animals, and animals recovered from vibration (blue) and their corresponding Boltzmann fits; $n \geq 6$ for all strains. Error bars represent $S E M$ of responses at each displacement. $\boldsymbol{F}$, Mean \pm SEM of the $D_{50}$ and $k$ values of the indicated cells in wild-type animals. $\boldsymbol{G}$, Sample calcium responses (blue) from control (top) and vibrated (bottom) animals. The GCaMP3 fluorescence levels are shown with arbitrary units (au). The displacement of each stimulus (black cross, in micrometers) is marked at each peak. Arrows indicate calcium peaks without stimuli. $\boldsymbol{H}-\boldsymbol{K}$, Statistics of calcium responses in AVA and AVD neurons with (white, V) or without (black, C) sustained vibration. Maximum fluorescence changes $(\boldsymbol{H})$ were shown instead of $\Delta F / F_{0}$ because baseline GCaMP3 fluorescence in the AVA neurons was reduced after vibration $(\boldsymbol{J})$, complicating the interpretation of $\Delta F / F_{0}$. This reduction of baseline fluorescence was likely due to a change in the baseline calcium level because antibody staining against GCaMP3 in vibrated animals showed no change in the amount of GCaMP3 expressed $(\boldsymbol{K})$. $\mathrm{D}_{10}$ was shown $(\boldsymbol{I})$ instead of $\mathrm{D}_{50}$ because estimation of the $\mathrm{D}_{10}$ values are less sensitive to the fast habituation in these cells.

sponse had reached the baseline or had plateaued. The timing between two stimuli could thus be different, but such timing differences did not change the response over the small number of trials in each experiment (data not shown). Calcium responses (after background subtraction) at different displacements were normalized to the maximum calcium response for each animal. All calcium responses from multiple animals of the same genotype and treatment were then pooled together and fitted 
with a Boltzmann equation using Microsoft Excel in the form of the following:

$$
\mathrm{R}=\frac{1}{1+e^{k\left(D-D_{50}\right)}}
$$

where $\mathrm{R}$ is the normalized calcium response, and $\mathrm{D}$ is the probe displacement. Additionally, calcium responses from the same animal were fitted with a Boltzmann equation to calculate $\mathrm{D}_{50}$, the slope factor $k$, and maximum calcium response for each animal tested, and their means and SEMs were used for evaluating statistical significance of the changes in $\mathrm{D}_{50}, k$, and maximum calcium response across different strains. The $\mathrm{D}_{50}$ and $k$ obtained by fitting all data points for a particular strain showed only small discrepancies from the mean $\mathrm{D}_{50}$ and $k$ calculated from individual animals and falls within 1 SEM from the mean $\mathrm{D}_{50}$ and $k$ values. Calcium imaging in the interneurons was performed similarly except that only adult animals were used. Animals were stimulated every $20 \mathrm{~s}$ once a response was observed to minimize the effect of habituation. Each animal was tested once at each voltage because of stronger habituation than the signals in the TRNs. The actual displacement of the probe at a particular voltage was measured using DIC images from multiple animals that were acquired after the calcium recordings were finished. The displacements of the probe were essentially identical (within 10\%) across individual animals and genotypes.

Calcium imaging of TRNs cultured on coverslips (Topalidou and Chalfie, 2011) was performed according to Suzuki et al. (2003). pat-2 or unc-112 ALM cells were selected by finding GCaMP3-positive and RFPnegative cells with one long process only. ALM cells from other strains were selected by finding GCaMP3-positive cells with one long process only. Potassium depolarization was performed according to Suzuki et al. (2003): cells were perfused using an extracellular saline (145 mM NaCl, 5 mм KCl, $2 \mathrm{~mm} \mathrm{CaCl}_{2}, 1 \mathrm{~mm} \mathrm{MgCl}_{2}, 10 \mathrm{~mm}$ HEPES, and $10 \mathrm{~mm}$ D-glucose, $\mathrm{pH} 7.2$, and adjusted to $340 \mathrm{mOsm}$ with sucrose) and depolarized with extracellular saline with $110 \mathrm{~mm} \mathrm{KCl}$ and $40 \mathrm{~mm} \mathrm{NaCl}$. The maximum calcium change within five seconds from the initiation of the response was measured.

Scoring of TRN morphological defects. A TRN process was scored as ensheathment defective if it was close to the muscle in adults for more than half its length when examined under $20 \times$ magnification. For RNAitreated animals (Fig. $3 F$ ), an ALM process was scored as attachment defective if the ALM cell body was squeezed into a half-circle shape (an indication of its adjacency to muscle) instead of the normal raindrop shape. We scored an ALM cell as migration defective when the cell body was anterior either to the mid-point between terminal bulb of the pharynx and the vulva, or to the AVM cell body. $P$ values were calculated using Fisher's exact test.

Imaging and single-molecule mRNA FISH. All images were taken on a Zeiss Observer Z1 microscope with a Photometrics CoolSnap HQ ${ }^{2}$ camera. We performed single-molecule mRNA FISH as described previously (Topalidou et al., 2011). The numbers of transcripts per cell were counted manually. Three independent tests were performed and the results were pooled.

Statistics. Results from touch assays, channelrhodopsin-2 assays, and antibody staining were compared using Student's $t$ test. Categorical data from vibration assays, attachment defects, and migration defects were compared using Fisher's exact test. smFISH data were compared using Mann-Whitney's $U$ test. All $p$ values reported are after Bonferroni corrections.

\section{Results}

\section{Multiple conditions alter touch sensitivity}

The response to gentle touch in C. elegans habituates with repeated stimuli (Chalfie and Sulston, 1981; Rankin et al., 1990). We induced habituation by placing plates of animals on speakers producing a $50 \mathrm{~Hz}$ vibration (1.5 $\times g$ average acceleration), subjecting them to varying periods of stimulation, and testing their touch sensitivity $5 \mathrm{~min}$ after the end of stimulation. The anterior and posterior responses habituated with different time courses

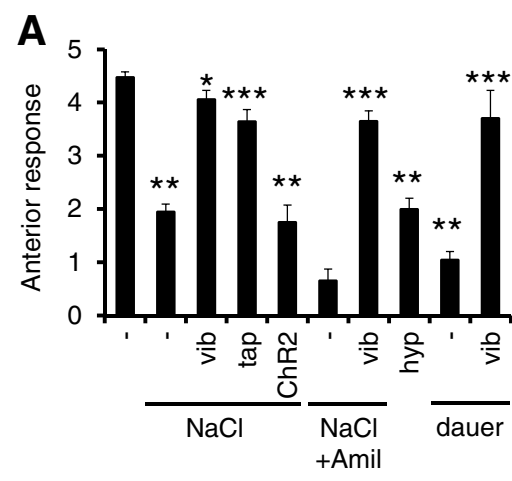

B

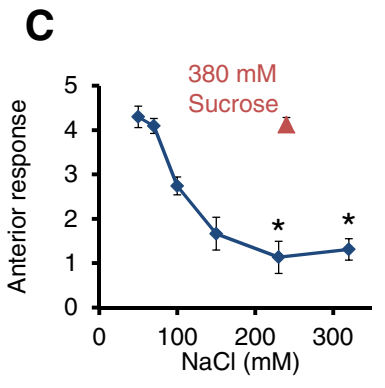

D
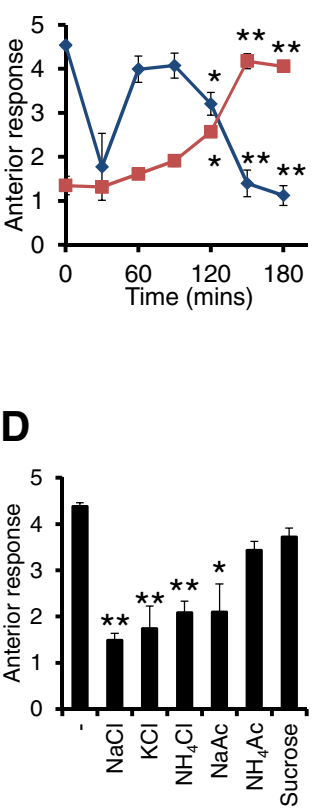

Figure 2. Modulation of touch sensitivity by stress and vibration. $A$, Anterior touch sensitivity (mean $\pm S E M)$ in control animals (-), dauer larvae (dauer), or animals subjected to sustained vibration (vib), tapping (tap), or sustained channelrhodopsin-2 activation (ChR2). Additionally animals were treated with $230 \mathrm{~mm} \mathrm{NaCl}(\mathrm{NaCl}), 230 \mathrm{~mm} \mathrm{NaCl}$ with $2 \mathrm{~mm}$ amiloride ( $\mathrm{NaCl}+$ Amil), or $1 \% \mathrm{O}_{2}$ (hyp). The amiloride-treated animal contained a bus-17 mutation; ${ }^{* *} p<0.005$ compared with control, and ${ }^{*} p<0.05,{ }^{* * *} p<0.005$ compared with the respective control under each condition, $N \geq 3$ for all strains. $\boldsymbol{B}$, Anterior touch response (mean \pm SEM) of wild-type animals at the noted time points after they were transferred from $50 \mathrm{~mm} \mathrm{NaCl}$ to $230 \mathrm{~mm} \mathrm{NaCl}$ (blue) or from $230 \mathrm{~mm} \mathrm{NaCl}$ to $50 \mathrm{~mm} \mathrm{NaCl}$ (red). $N \geq 4$ for all time points; ${ }^{*} p<$ $0.01,{ }^{* *} p<0.005$. C, Anterior touch response (mean \pm SEM) of wild-type animals grown on NGM plates with the specified concentration of $\mathrm{NaCl}$ or with $50 \mathrm{~mm} \mathrm{NaCl}$ and $380 \mathrm{~mm}$ sucrose; $N=3,{ }^{*} p<0.05$. D. Anterior touch response (mean $\pm \mathrm{SEM}$ ) of wild-type animals grown on NGM plates supplemented with $180 \mathrm{~mm}$ of the specified salts or $380 \mathrm{~mm}$ sucrose; $N \geq 6,{ }^{*} p<$ $0.05,{ }^{* *} p<0.005$

(Fig. 1A). Vibration caused posterior touch sensitivity to be increasingly lost over $24 \mathrm{~h}$. In contrast, although animals lost touch sensitivity to anterior touch if stimulated for less than $2 \mathrm{~h}$, they were sensitized back to nearly wild-type levels after $2 \mathrm{~h}$ (Fig. 1A). Longer period of vibration did not further increase touch sensitivity. A similar increase in posterior touch sensitivity after habituation was not seen (Fig. 1A). The greatest sensitization occurred when animals were vibrated for more than $2 \mathrm{~h}$ at a frequency of 50 $\mathrm{Hz}$ and with average acceleration $\geq 1 \times g($ Fig. $1 B-D)$. We further substantiated these findings using GCaMP3 imaging: vibration reversibly reduced the displacement required for $50 \%$ activation $\left(D_{50}\right)$ in the ALM neurons $(p<0.02)$, but not in the PLM neurons (Fig. $1 E, F)$. In addition, ALM neurons of treated animals produced spontaneous calcium spikes without a mechanical stimulus; no such spikes were observed in untreated animals (Fig. 1G). The appearance of the spikes suggests that the vibrated animals detected either background vibrations from the microscope stage or stimuli induced by the contraction of body wall muscles. Thus, prolonged vibration specifically increased the touch sensitivity of ALM neurons and counteracted habituation to maintain a normal response.

In addition to increased sensitivity of the TRNs, the sensitized behavioral response could also be caused by changes in the downstream circuits. The anterior ALM neurons synapse onto the AVD interneurons neurons, which synapse onto the AVA interneurons; these interneurons drive backward movement 
(Chalfie et al., 1985). Calcium imaging in these cells revealed a similar reduction in the displacement needed to reproducibly elicit a calcium response as in ALM neurons, and no increase in the maximum amplitude of calcium response by saturated stimulation except for a reduced baseline level in the AVA cells following sustained vibration (Fig. $1 H-K)$. Thus, synaptic changes are unlikely to contribute to sensitization.

In contrast to the stimulating effect of prolonged vibration, several stress conditions reduced the anterior touch response (Fig. 2A). Wild-type animals grown on high salt $(230 \mathrm{~mm} \mathrm{NaCl}$, but not $380 \mathrm{~mm}$ sucrose $+50 \mathrm{~mm} \mathrm{NaCl}$; Fig. $2 B-D$ ) or under hypoxic conditions $\left(1 \% \mathrm{O}_{2}\right)$ or animals that had developed into dauer larvae had reduced anterior touch sensitivity (Fig. 2A). The touch insensitivity, however, was restored when the animals were subjected to several hours of sustained vibration or repeated tapping $(1 \mathrm{~Hz}$; Fig. 2A). To test if activation of the MEC-4 mechanotransduction channel was needed for sensitization by vibration, we blocked the activation of MEC-4 mechanotransduction channels by treating bus- 17 animals with amiloride during prolonged vibration and tested the animals after recovery from amiloride (the amiloride treatment effectively reduced anterior touch sensitivity of bus-17 animals from wild-type level to $0.3 \pm 0.1$ responses out of five touches, $N=3$ ). Prolonged vibration in the presence of amiloride restored touch sensitivity (Fig. $2 A)$, indicating that activation of the MEC-4 channel is not required for sensitization. In addition sensitization was not induced by continuous activation of the TRNs through channelrhodopsin-2 (Nagel et al., 2005; Fig. 2A), suggesting that activation of the TRNs without mechanical stimulation is not sufficient to induce sensitization. These data suggest that vibration-induced sensitization requires a different force sensor.

\section{Integrin signaling modulates mechanical sensitivity}

Integrins and focal adhesion proteins sense cellular stretching forces and induce long-term cellular changes (Roca-Cusachs et al., 2012). Even though the focal adhesion proteins are expressed in mechanosensory cells, including the TRNs and vertebrate hair cells (Fig. 3A), they are unlikely to mediate the rapid, submillisecond mechanosensory transduction seen in neurons (Chalfie, 2009) because integrinmediated mechanosensation is usually slow (tens of seconds; Vogel and Sheetz, 2009). Nonetheless, a role of these proteins in mechanosensation is suggested by the loss of touch sensitivity that occurs when focal adhesion proteins are reduced using cell-

E
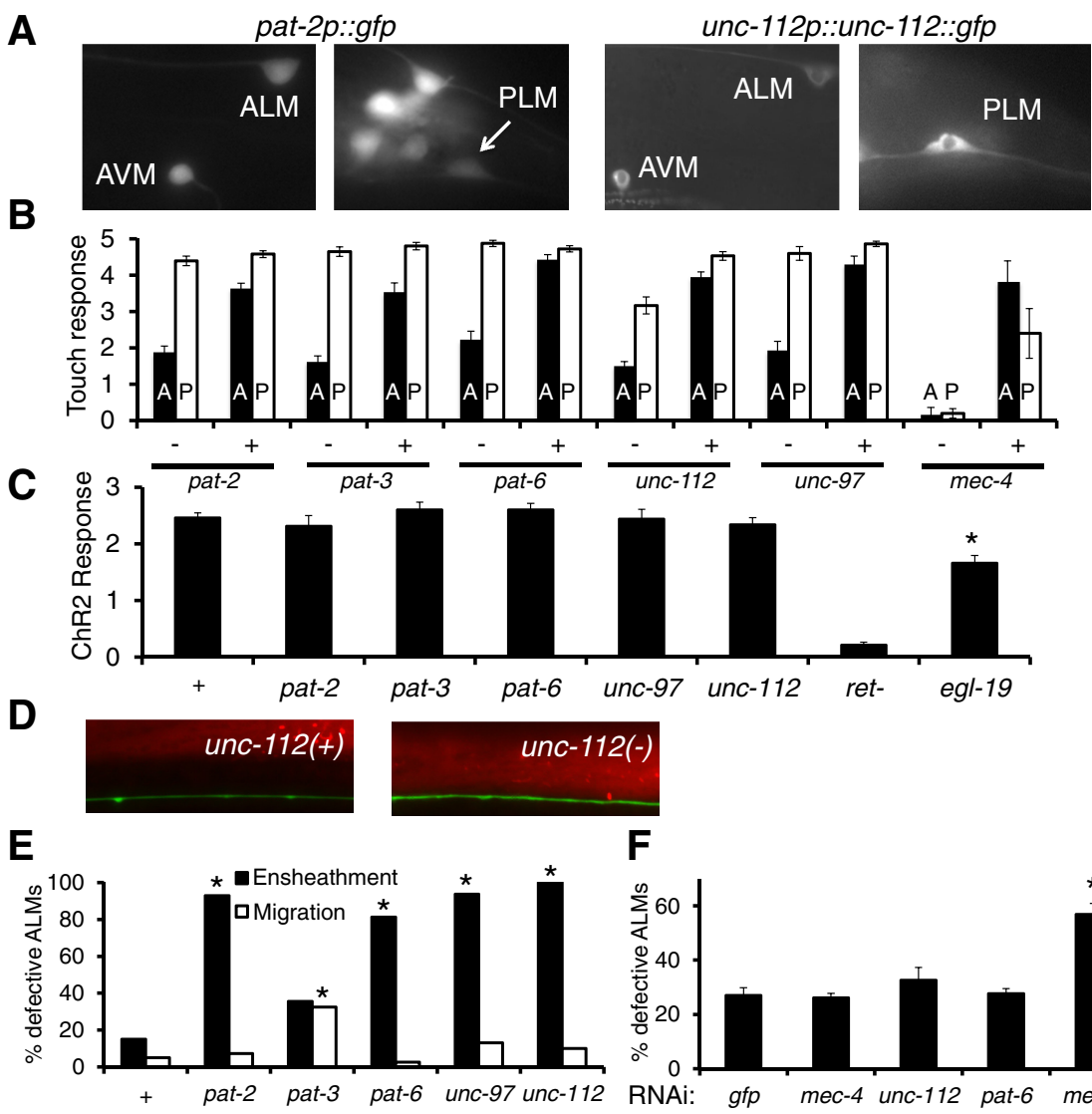

$\mathbf{F}$

Figure 3. Effect of focal adhesion mutants on TRN function. $\boldsymbol{A}$, The expression of pat-2p::gfp or unc-112p::unc-112::gfp in ALM, AVM, and PLM TRNs of animals fed bacteria containing dsRNA against $g f p$. Because of the inefficient systemic RNAi in the nervous system, gfp expression in the body-wall muscle, but not in the neurons, is reduced, allowing visualization of GFP in the TRNs. Other focal adhesion proteins have been shown to be expressed in the TRNs and the vertebrate hair cells (Gettner et al., 1995; Hobert et al., 1999; Littlewood Evans and Muller, 2000; Mackinnon et al., 2002; Lin et al., 2003). B, Anterior (A, black) and posterior (P, white) responses (mean \pm SEM of responses of individual animals) of mosaic animals with $(+)$ or without $(-)$ the rescuing arrays of the indicated genes in the TRNs. For the focal adhesion genes, $n>20$ for anterior responses, and $n>15$ for posterior responses. For mec $-4, n>10$. For all anterior responses, $p<0.005$ between $(+)$ and $(-)$ animals. $C$, Response (mean \pm SEM of responses of individual animals) to three light pulses from focal adhesion mosaic animals lacking the rescuing arrays of the indicated genes in the TRNs but expressing channelrhodopsin-2 (ChR2) in the TRNs and from egl-19 animals expressing channelrhodopsin-2 in the TRNs; $n \geq 20$ for all strains tested, ${ }^{*} p<0.05$ compared with the wild-type. D, ALM processes (green) and the body-wall muscle (red) in unc-112 mosaic animals with or without unc-112 in the ALM cells. The ALM process is normally ensheathed by the hypodermis, which separates the ALM process from the body-wall muscle in adults. ALM processes that are not ensheathed appear adjacent to the body-wall muscle. The ALM cell body would also be pressed against the body-wall muscle, assuming a half-circle shape instead of the normal raindrop shape. The PLM processes had similar defects, yet retained the touch sensitivity, suggesting that the ensheathment defect alone did not cause touch insensitivity. $\boldsymbol{E}$, Fractions of TRNs showing ensheathment defects (black) or migration defects (white); $n>15$ for ensheathment data and $n \geq 20$ for migration data; ${ }^{*} p<0.002$ compared with wild-type. The migration defect seen in pat-3 animals could not account for the reduced touch sensitivity either, because animals lacking the second $C$. elegans $\alpha$-integrin gene, ina-1, were touch sensitive despite having similar migration defects (Baum and Garriga, 1997; data not shown). $\boldsymbol{F}$, Fractions of ensheathment-defective ALM cells in TU3595 animals fed with neuron-enhanced RNAi against $g f p$, mec-4, unc-112, pat-6, or mec-1. See Materials and Methods for detailed scoring standard. $N \geq 3,{ }^{*} p<0.05$ compared with gfp RNAi control. The RNAi-treated animals, except for the gfp control, had reduced touch sensitivity, suggesting that the ensheathment defect cannot solely account for the reduced touch sensitivity.

specific RNAi or partial loss-of-function mutations (Hobert et al., 1999; Calixto et al., 2010). We wondered, however, whether the focal adhesion proteins contributed to force sensing for sensitization.

To circumvent the embryonic lethality associated with the complete loss of the focal adhesion genes, we tested touch sensitivity in animals that were mosaic for null alleles (Fig. $3 B$ ). Loss of pat-2/ $\alpha$-integrin, pat-3/ $\beta$-integrin, unc-97/PINCH, unc-112/ Mig-2, or pat-6/actopaxin in the anterior TRNs (the two ALM 
cells and the AVM cell) yielded animals that were partially insensitive to anterior touch. (Loss of these genes in the posterior TRNs, the two PLM neurons, did not reduce touch sensitivity.) The partial loss of anterior sensitivity was not caused by general cellular dysfunction or changes in downstream circuits, because ALM neurons expressing channelrhodopsin-2 (Nagel et al., 2005) and containing or lacking the rescuing arrays of the focal adhesion genes were equally capable of inducing backing when activated by blue light (Fig. 3C). In contrast, animals with reduced activity of the L-type voltage-gated calcium channel EGL-19 responded less to blue light activation of channelrhodopsin-2. These data indicate that the focal adhesion proteins do not disrupt the channelrhodopsin-2 response and are likely to affect an early stage of mechanosensation.

The TRNs lacking rescuing arrays had normal morphology except for minor migration defects seen in ALM cells lacking pat-3 and the failure of the ALM and PLM processes to separate from the muscle that normally occurs after the TRN processes are ensheathed by the surrounding hypodermis in adults (Fig. $3 D, E$; Gettner et al., 1995). A similar role for integrins in the anchoring of neuronal processes to epidermal cells occurs in Drosophila (Kim et al., 2012). These defects, however, cannot solely account for the reduced touch sensitivity (Fig. $3 F$ ).

Focal adhesion proteins did, however, modulate the sensitivity of the ALM neurons as measured by an increase in $\mathrm{D}_{50}$ in pat-2 $(2.6 \pm 0.2 \mu \mathrm{m}$, mean \pm SEM, $n=11, p<0.0001, k=1.2 \pm 0.1)$ and $u n c-112$ mutants $(1.7 \pm 0.2 \mu \mathrm{m}, n=6, p<0.005, k=1.6 \pm$ $0.1)$ compared with wild-type animals $(1.1 \pm 0.1 \mu \mathrm{m}, n=26, k=$ $3.3 \pm 0.3$; Fig. 4A). Loss of pat-2, but not unc-112, also reduced maximum calcium response both in vivo and in cultured cells depolarized by high potassium (Fig. $4 B, C$ ), suggesting an additional role in regulating calcium influx.

\section{Integrins mediate vibration-induced sensitization through AKT and FOXO}

Using neuron-enhanced feeding RNAi, we screened conserved signaling genes whose products may interact with or affect integrin signaling (Zaidel-Bar, 2009) and found that insulin signaling and several other signaling pathways were required for optimal touch sensitivity (Table 2). Insulin signaling prevents dauer formation in $C$. elegans through the successive activation of the DAF-2/insulin receptor, the AGE-1/PI3 kinase, the PDK-1/3phosphoinositide-dependent kinase, and the redundantly acting AKT-1 and AKT-2/AKT, which inhibit the activity of the DAF16/FOXO transcription factor ( $\mathrm{Hu}, 2007)$. Mutations in daf-2, age-1, pdk-1, and akt-1 reduced anterior touch sensitivity (Fig. $5 A$ ). Both akt-1 and akt-2 are expressed in the TRNs (Fig. 5B). Loss of akt-2, however, did not produce touch insensitivity by itself, but further reduced anterior touch sensitivity of akt-1 mutant (from $2.5 \pm 0.1$ responses to $0.7 \pm 0.2$ responses, $N \geq 3, p<$ 0.0001 ), suggesting that akt-2 plays a minor role in regulating touch sensitivity. None of these mutations affected posterior touch sensitivity except for the daf-2(m65)-null mutation (other temperature-sensitive daf-2 mutations, including e979, $m 41$, and sa193, which produce similar dauer formation and lifespan phenotypes as $m 65$, only reduced anterior touch sensitivity; Fig. $5 C$ ). As expected from the known pathway, the touch insensitivity of daf-2 animals was suppressed by the loss of daf-16 (Fig. 5D) or a gain-of-function mutation in $p d k-1$ [mg142; $p d k-1(g f)]$ (from $0.9 \pm 0.2$ responses to $4.1 \pm 0.1, N \geq 4, p<0.0001)$. Moreover TRN-specific expression of akt-1(+) restored the anterior touch sensitivity of akt- 1 animals (from $2.6 \pm 0.3$ responses to $4.0 \pm 0.3$
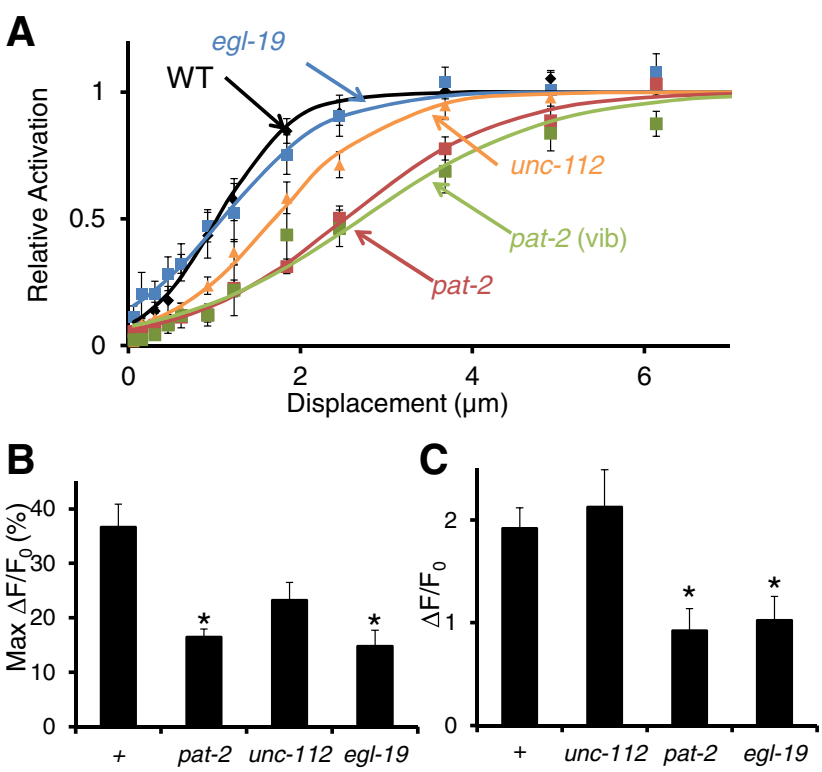

Figure 4. The calcium response to touch in focal adhesion mutants. $\boldsymbol{A}$, Normalized calcium response (mean \pm SEM at each given displacement) of wild-type, pat-2 mosaic animals, pat-2 mosaic animals subjected to sustained vibration, unc- 112 mosaic animals, and egl-19 animals and their corresponding Boltzmann fits using all data points for a particular strain; $n \geq 6$ for all strains. Wild-type data is reused from Figure $1 B$. $B$, Maximum calcium response (Max $\Delta F / F_{0}$ ) of ALM neurons to saturated stimulation from wild-type, pat-2 mosaic, unc-112 mosaic, and egl-19 animals; ${ }^{*} p<0.05$ compared with wild-type, $n \geq 6$ for all strains. C, Calcium responses (mean $\Delta F / F_{0} \pm$ SEM) of cultured ALM cells from wild-type, unc-112, pat-2, and egl-19 animals to potassium depolarization; ${ }^{*} p<0.05$ compared with wild-type response, $n \geq 9$ for all groups. ALM neurons from both pat-2 and egl-19 mutants, either in vivo or cultured, gave a decreased maximum calcium signal without a decrease in sensitivity $\left(D_{50(\mathrm{egl}-19)}=1.0 \pm 0.3\right.$ $\mu \mathrm{m}, n=5, k=2.0 \pm 0.6)$, indicating that the maximum calcium response and sensitivity do not depend on each other. These results suggest that pat-2 and egl-19 mutations changed the calcium response independently of mechanotransduction and of UNC-112. Therefore, PAT-2 additionally modulates the calcium response.

responses, $N \geq 3, p<0.0001$ ), indicating that the pathway was active in the TRNs.

Focal adhesion complexes phosphorylate and activate AKT kinases in mammalian cells (Persad et al., 2001). To test if integrin signaling modulates $C$. elegans touch sensitivity through AKT-1, we overexpressed focal adhesion genes in the TRNs in pdk-1 and akt-1 mutants. Overexpressing unc-112 and pat-6 in the TRNs of daf-2(m65), pdk-1(sa680), but not akt-1(ok525) animals restored their touch sensitivity (Fig. 6A). Increasing insulin signaling by akt-1 (mg144), pdk-1(mg142), or daf-16(mgDf50) restored the anterior touch sensitivity of unc-112 and pat-2 mosaic animals (Fig. 6B). These data indicate that insulin and integrin signaling converge on AKT-1 to modulate touch sensitivity and compensate for each other. The focal adhesion proteins are unlikely to act downstream of insulin signaling, as suggested by quantitative PCR results of Suzuki and Han (2006), because single molecule mRNA fluorescent in situ hybridization (smFISH) revealed no change in the number of unc-112 transcripts in daf2(e1370) animals (data not shown).

Sustained vibration restored anterior touch sensitivity to daf-2 and pdk-1 animals, but not to unc-112, pat-2 or akt-1 mutants (Fig. 6C), indicating that vibration compensates for loss of insulin signaling through the focal adhesion proteins and AKT-1, but not PDK-1. Calcium imaging confirms that vibration did not change the sensitivity of ALM neurons lacking pat-2 (Fig. 4A). Because focal adhesions are implicated in sensing force, these data suggest that the focal adhesions act as secondary mechano- 
sensors in the ALM neurons, although we cannot rule out that they act immediately downstream of the receptor.

If integrins act as secondary mechanosensors, they must bind to ECM components so external force can be transmitted through the hypodermis to the TRNs (Roca-Cusachs et al., 2012). him-4 mutant animals lack most of the ECM around the TRN processes and the attachment between the processes and the hypodermis (Vogel and Hedgecock, 2001), and should prevent integrin activation. Although him-4 animals respond to touch (Vogel and Hedgecock, 2001), using our modified touch test (see Materials and Methods), we detected a reduction in touch sensitivity (Fig. 6C,D). Anterior sensitivity was restored to him-4 animals by expression of the gain-of-function $p d k-1$ allele in the TRNs (Fig. 6D), but not by sustained vibration (Fig. 6C), suggesting that integrin signaling cannot be activated by external force without the ECM and/or attachment to the hypodermis.

\section{Hypoxia and the dauer state regulate TRN touch sensitivity through the reduction in INS-10}

TRNs are unlikely to sense hypoxia, high salt, or the dauer state directly. These conditions must be sensed by other neurons that then signal to the TRNs. Because insulin signaling alters the anterior touch response, we tested the effect on touch sensitivity of the loss of the 40 genes encoding insulin-like peptides (Pierce et al., 2001) using mutants with loss-offunction alleles or RNAi-treated animals. Mutation or reduction of ins-10 and ins-22 caused anterior touch insensitivity (a third gene, ins-33, may affect TRN development; Fig. 7A).

INS-10 modulates anterior touch sensitivity through its release from two pharyngeal neurons: the M4 motor neuron and the 15 interneuron (Fig. 7B). Laser ablation of both the M4 and I5 neurons in late L4 stage animals resulted in adults whose anterior touch sensitivity mimicked the loss of ins-10 within $24 \mathrm{~h}$ of ablation (Fig. 7C), but whose posterior touch sensitivity did not change (data not shown). Ablation of either cell alone resulted in little or no reduction of anterior touch sensitivity compared with controls. Because neither M4 nor I5 connects synaptically to the TRNs or their downstream interneurons (Albertson and Thomson, 1976; Chalfie et al., 1985), INS-10 acts hormonally on the TRNs.

INS-10 expression was greatly reduced by hypoxic conditions and dauer arrest (Fig. 7D-G). Under the same conditions, GFP or RFP expressed in the pharyngeal muscles (driven by ceh-22p or
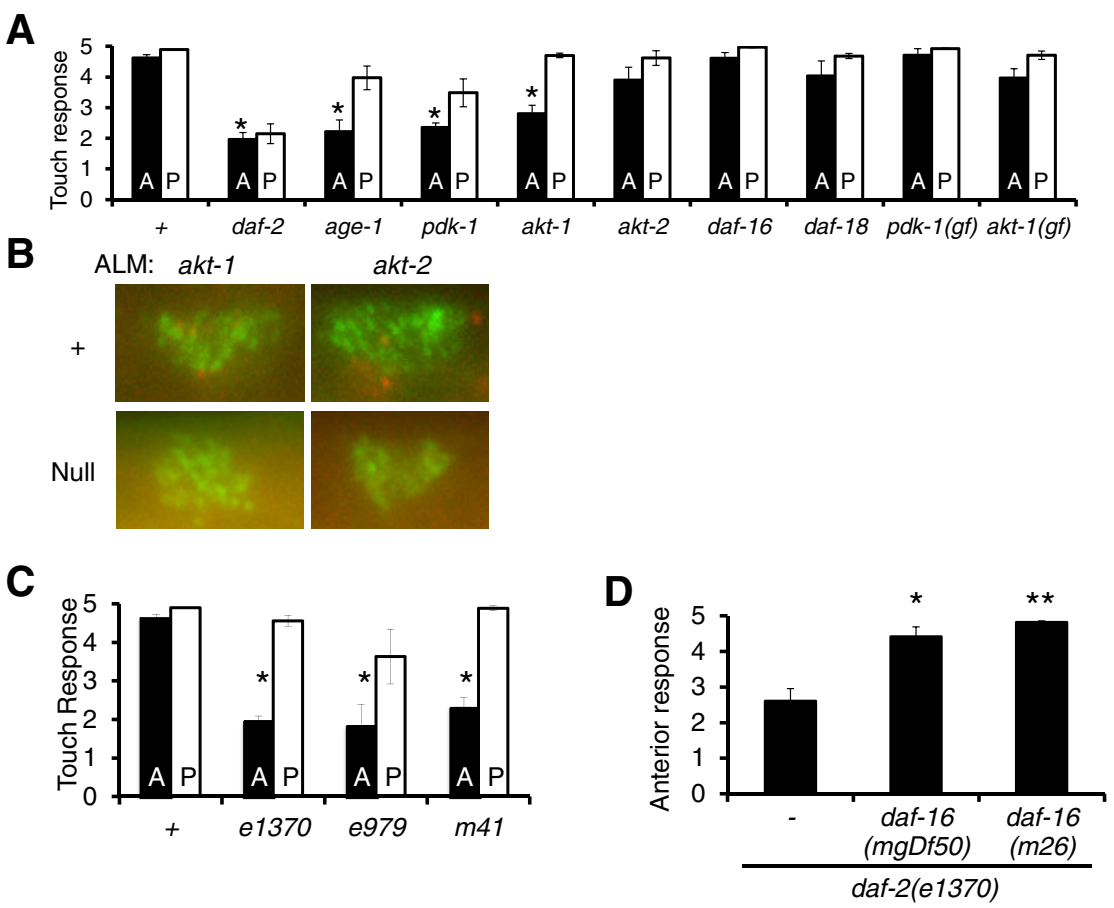

Figure 5. Insulin signaling affects touch sensitivity. $\boldsymbol{A}$, Anterior ( $A$, black) and posterior $(P$, white) response (mean \pm SEM) of animals with the indicated phenotypes; ${ }^{*} p<0.005$ compared with wild-type, $N \geq 3$ for all strains. $B$, smFISH of akt-1 (left) or akt-2 (right; red), and mec-18 (green) in wild-type (+) or the respective null (null) mutants. The positions of the mec-18 dots delineate the shape of the ALM cell body. C, Anterior (black) and posterior (white) response (mean \pm SEM) of daf-2(e1370), daf-2(e979), and daf-2(m41) animals; $N=3,{ }^{*} p<0.001$ compared with wild-type. $\boldsymbol{D}$, Anterior touch response (mean \pm SEM) of daf-2(e1370), daf-16(m26); daf-2(e1370), and daf-16(mgDf50); daf-2(e1370) animals; ${ }^{*} p<0.05,{ }^{* *} p<0.0005$ compared with daf- 2 alone, $N \geq 3$ for all strains.
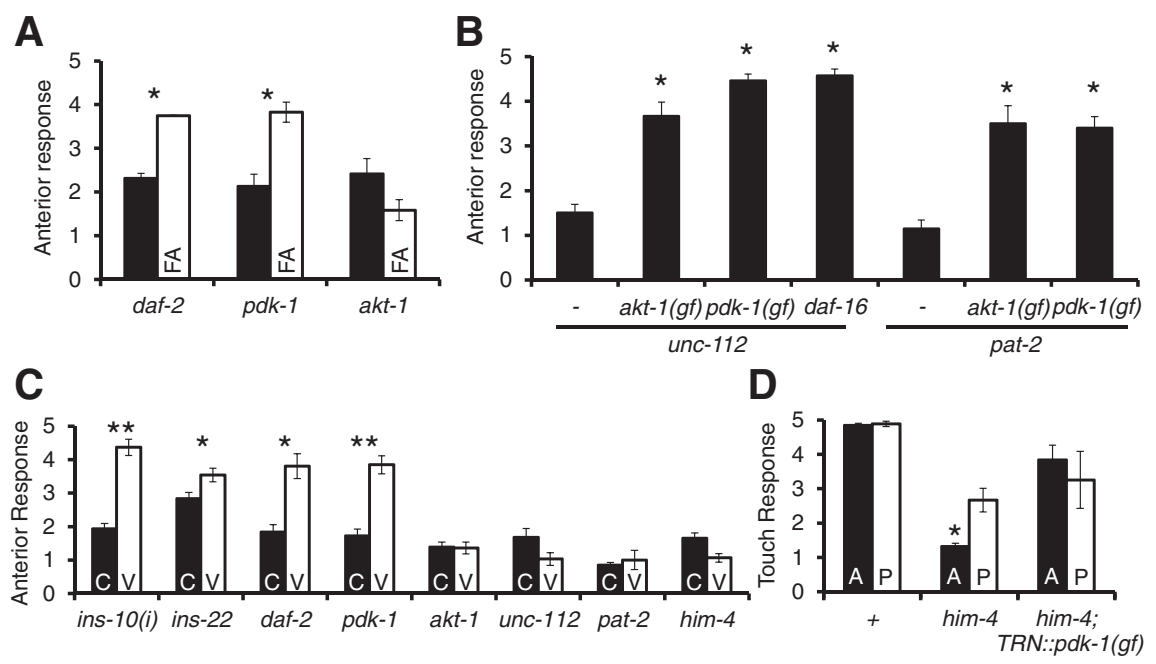

Figure 6. Integrin and insulin signaling converge to affect touch sensitivity. $\boldsymbol{A}$, Anterior response of $d a f-2(m 65)$, pdk-1, and akt- 1 animals with (white) or without (black) added focal adhesion (FA) proteins UNC-112 and PAT- 6 in the TRNs; ${ }^{*} p<0.005$ with or without UNC-112/PAT-6, $N \geq 3$. B, Effect of akt- $1(g f), p d k-1(g f)$, and daf- 16 on the anterior touch response of unc-112 or pat-2 mosaic animals. Values are the means \pm SEM of responses of individual animals; $n>10,{ }^{*} p<0.005$ compared with unc-112 or pat-2 alone. $C$, Anterior touch sensitivity of animals with the indicated phenotypes grown with ( $V$, white) or without $(C$, black) vibration; ${ }^{*} p<0.05$, ${ }^{* *} p<0.002$ with or without vibration, $N \geq 3$ for all strains. $D$, Anterior (A, black) and posterior ( $\mathrm{P}$, white) touch response of wild-type, him- 4 animals, and him-4 animals carrying mec-3p::pdk-1( gf); ${ }^{*} p<0.005$ compared with wild-type anterior response and $p<0.05$ compared with him- $4+$ mec-3p::pdk-1(gf); $N \geq 3$.

$m y o-2 p)$ or the TRNs (mec-3p) changed much less. These changes in expression were not caused by starvation because starved L3 animals did not show them (Fig. 7D). These data suggest that the reduction of INS-10 expression was not caused solely by a general 
A
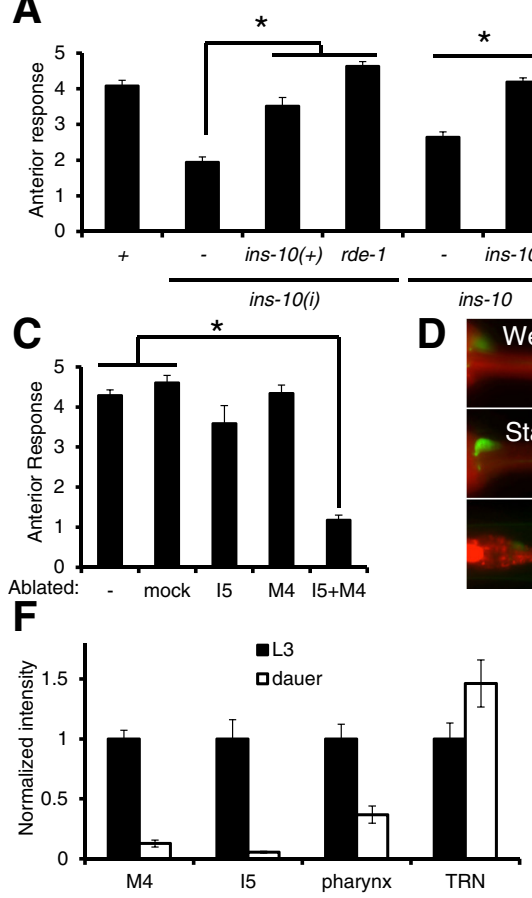

B

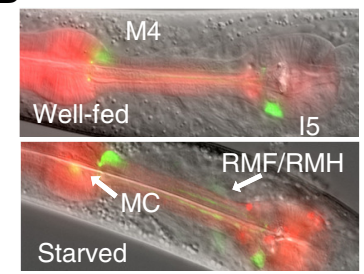

reduction of insulin signaling in the anterior TRNs and the subsequent loss of touch sensitivity.

\section{ASE releases ins-22 to modulate touch sensation}

The loss of ins-22(tm4990) also reduced anterior touch sensitivity (Fig. 7A) without affecting normal development or dauer formation (data not shown). As with ins-10, the ins-22 touch insensitivity was rescued by the wild-type gene (Fig. 7A), daf-16, TRN::pdk-1(gf) (Fig. 9A), and vibration (Fig. 6C).

ins-22 is expressed strongly in both ASE cells (Fig. 9B), sensory neurons that sense the ions $\left(\mathrm{Na}^{+}, \mathrm{Cl}^{-}\right.$, but not $\mathrm{CH}_{3} \mathrm{COO}^{-}$and $\mathrm{NH}_{4}{ }^{+}$; Ortiz et al., 2009) whose elevation reduces anterior touch sensitivity (Fig. 2D). che-1 animals, which lack both ASE cells, have reduced anterior touch sensitivity that can be restored by TRN::pdk-1(gf) (Fig. 9C), suggesting that INS-22 from the ASE cells regulates TRN touch sensitivity. Consistent with this hypothesis, INS-22 expression was reduced when the animals were grown in high salt (Fig. 9B,D), and the reduced touch sensitivity produced by high salt was rescued by $a k t-1(g f), p d k-1(g f), T R N:: p d k-1(g f)$, and daf-16 or TRN overexpression of UNC-112/PAT-6 (Fig. 9E). Expressing daf-16a but not daf-16b in the TRNs of daf-16 animals caused them to reduce anterior touch sensitivity on high salt.

Animals without ins-22, however, were more sensitive to anterior touch than either che-1 mutants or wild-type animals grown on high salt (Fig. $9 A, C, E)$. Moreover, we were unable to detect significant changes in the sensitivity of ins-22 animals $\left(\mathrm{D}_{50}=0.9 \pm 0.2 \mu \mathrm{m}, n=10, k=\right.$ $3.7 \pm 0.8)$. These results suggest that loss of additional components other than INS-

reduction of translation during hypoxia (Connolly et al., 2006) or of transcription in dauer larvae (Dalley and Golomb, 1992).

Animals generating RNAi against ins-10 [ins-10(i)] were less sensitive to mechanical stimulation $\left(\mathrm{D}_{50}=2.1 \pm 0.3 \mu \mathrm{m}, n=16\right.$, $p<0.001, k=2.2 \pm 0.4$; Fig. $8 A)$ than wild-type animals $\left(\mathrm{D}_{50}=\right.$ $1.1 \pm 0.1 \mu \mathrm{m}, k=3.3 \pm 0.3$, as noted above) without changing the maximum calcium response (data not shown). The anterior touch insensitivity of ins-10(i) animals was restored by akt-1(gf), $p d k-1(g f)$, or by an equivalent construct of $p d k-1(g f)$ expressed only in the TRNs [TRN::pdk-1(gf)] (Fig. 8B), suggesting that INS-10 acts via the insulin signaling pathway in the ALM neurons. Because activation of integrin signaling compensates for the loss of insulin signaling in the TRNs (Fig. 6A), we expected and saw that the touch insensitivity of ins-10(i) was restored by overexpressing UNC-112/PAT-2 in the TRNs and by vibration (Figs. 6C, 8B). Moreover, hypoxia and the dauer state did not cause anterior touch insensitivity in akt-1(gf), daf-16, and TRN::pdk-1(gf) animals (Fig. 8C,D). These data suggest that hypoxia and the dauer state prevent the release of INS-10 from M4 and I5, causing a
22, perhaps other neuropeptides from the ASE neurons, signals high salt conditions to the TRNs.

\section{Modulation of touch sensitivity adapts animals to diverse conditions}

A striking aspect of the effects of high salt, hypoxia, dauer, and prolonged vibration is that they change only anterior touch sensitivity. Anterior touch, but not posterior touch, causes an initial backing usually followed by a turn so animals go in a new forward direction (Croll, 1975; Chalfie and Sulston, 1981). Therefore, reducing anterior touch sensitivity may cause wild-type animals to change movement directions less in response to nonlocalized mechanical distractions, such as short vibratory pulse, which activates both anterior and posterior TRNs. Indeed, ins-10(i) animals moved backward less often than wild-type animals (Fig. $10 \mathrm{~A})$ when given a short pulse of vibration $(0.5 \mathrm{~s}, 50 \mathrm{~Hz})$, and as a result changed directions less than wild-type (average turning angles are $22.5 \pm 2.6^{\circ}$ in wild-type vs $6.24 \pm 1.8^{\circ}$ in akt- 1 animals; $N=4, p<0.005)$. 
Such increased resistance to mechanical distraction may facilitate the completion of non-mechanosensory tasks. We tested how fast animals moved to a source of an attractant (diacetyl) when the plates were tapped once every $30 \mathrm{~s}$ (see Materials and Methods). This stimulus activates the TRNs. Although some habituation was seen, many animals still responded to the stimulus at the end of the trial. Fewer wild-type animals reached the diacetyl spot when the plate was tapped than when it was not tapped (Fig. $10 \mathrm{~B}, \mathrm{C}$ ), suggesting that the mechanosensory response interfered with the efficiency of chemotaxis. Wild-type dauers and ins-10(i) animals moved slower (data not shown) in general, but they were slightly more efficient at chemotaxis when tapped (Fig. $10 B, C$ ). To compensate for the slowing of the animals, we looked at ins-10(i) animals in which $p d k-1(g f)$ was expressed in the TRNs (Fig. $10 B, C$ ). These animals were sensitive to touch and, like wild-type animals, chemotaxed much slower with intermittent tapping. These results suggest that reduction of touch sensitivity in the TRNs was responsible for the change in chemotaxis efficiency when the plates were tapped. The change in anterior touch sensitivity allows animals to be less distracted by mechanical signals while they are responding to other senses.

Sensitization, in contrast, partially counteracts the effect of habituation that also occurs during sustained vibration: $\sim 10 \%$ more animals responded to a stronger vibratory pulse $(0.5 \mathrm{~s})$ given at $2 \mathrm{~h}$ during sustained vibration, when the cells were sensitized, rather than at $1 \mathrm{~h}$ (Fig. $10 D)$. This subtle yet statistically significant $(p<0.01)$ difference in responsiveness became more significant during the recovery following habituation. Wildtype animals recovered $95 \%$ of the unhabituated response to anterior touch after $10 \mathrm{~min}$ of rest following $3 \mathrm{~h}$ of vibration compared with $35 \%$ for akt-1 mutants (Fig. 10E). In contrast the posterior touch response showed no significant recovery by $30 \mathrm{~min}$ (Fig. 10F). Because akt-1 mutation blocks sensitization, these data suggest that sensitization facilitates the detection of stimuli during and after habituation.

\section{Discussion}

We have described and characterized the mechanisms and biological functions of several modulators of touch sensitivity (Fig. 11). Sustained stimulation sensitizes the TRNs, which relies not on the activation of the MEC-4 mechanosensory chan-

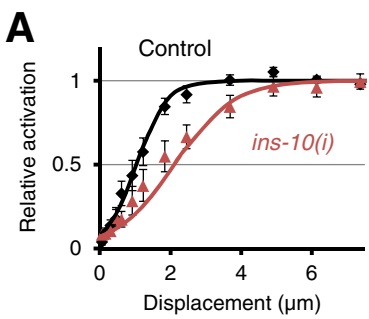

C

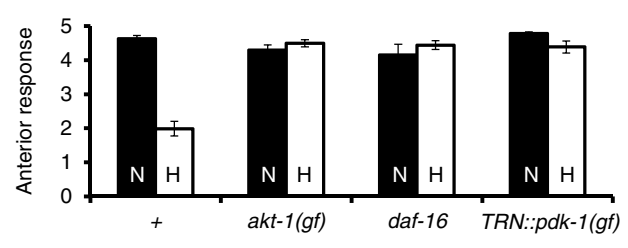

B

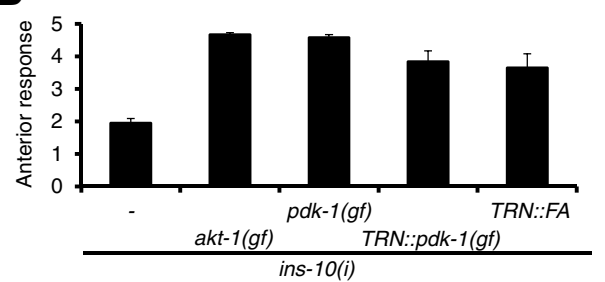

D

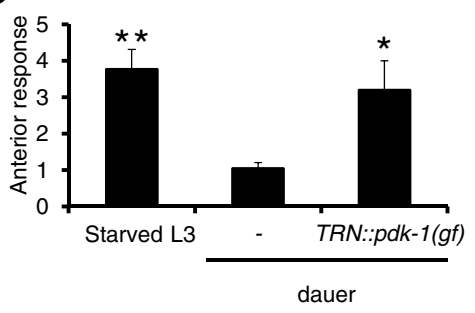

Figure 8. INS-10 regulates touch sensitivity through insulin signaling. $\boldsymbol{A}$, Normalized calcium responses (mean \pm SEM) of wild-type (black) and ins-10(i) (red) animals with different probe displacements, and their corresponding Boltzmann fits; $n \geq 16$ for both strains. The wild-type data were reused from Figure 1B. B, Anterior touch response (mean \pm SEM) of ins-10(i) animals with or without akt-1( gf), pdk-1( gf), mec-3p::pdk-1( gf), or mec-17p::unc-112::gfp and mec-17p::pat-6::gfp; $p<0.005$ for all other strains compared with ins-10(i) alone, $N \geq 3$. C, Anterior touch sensitivity (mean \pm SEM) of wild-type, daf-16, or akt-1( $g f$ ) animals, or animals carrying mec-3p::pdk-1 $g f$ ) grown under normoxic ( $\mathrm{N}$, black) or hypoxic ( $\mathrm{H}$, white) conditions; $N \geq 4$ for all strains and conditions tested, $p<0.005$ comparing hypoxic wild-type to other hypoxic strains. $\boldsymbol{D}$, Anterior touch sensitivity


$0.001,{ }^{* *} p<0.0005$ compared with wild-type dauer larvae.
A

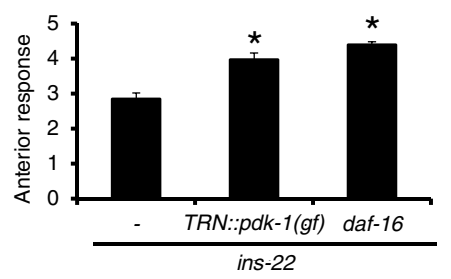

C

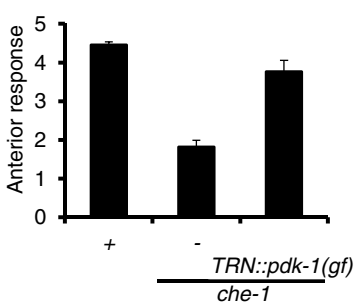

B

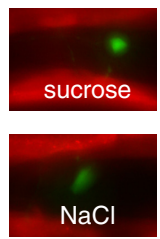

D

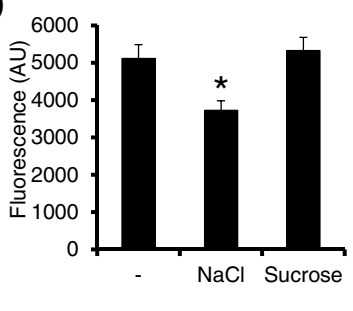

E

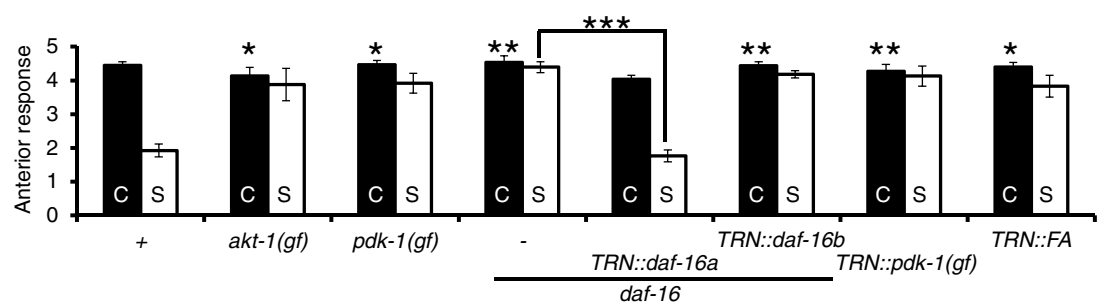

Figure 9. The ASE neurons and INS-22 regulates touch sensitivity. $\boldsymbol{A}$, Anterior touch response (mean $\pm \mathrm{SEM}$ ) of ins-22 animals, ins-22 animals expressing mec-3p::pdk-1( gf), and daf-16; ins-22 animals; ${ }^{*} p<0.05$ compared with ins-22, $N \geq 3$. $\boldsymbol{B}$, Expression of ins-22p::gfp in animals grown on high sucrose or high salt ( $\mathrm{NaCl})$. Images of myo-3p::mcherry were merged with green ins-22p::gfp images. C, Anterior touch response (mean \pm SEM) of wild-type and che-1 animals with or without mec-3p::pdk-1(gf); $N \geq 3, p<0.01$ between che-1 and the other two strains. D, Quantification of ins-22p::gfp in animals grown on control NGM plates and NGM plates supplemented with $180 \mathrm{~mm} \mathrm{NaCl}$ or 380 mm sucrose; $^{*} p<0.05$ compared with control and $p<0.005$ compared with sucrose, $n>15$ for all samples. $\boldsymbol{E}$, Anterior touch response (mean \pm SEM) of the indicated animals grown with $50 \mathrm{~mm} \mathrm{NaCl}$ (black, C) or with $230 \mathrm{~mm} \mathrm{NaCl}$ (white, S); ${ }^{*} p<0.05$ and ${ }^{* *} p<0.01$ comparing the respective strain on high salt to wild-type grown on high salt, ${ }^{* * *} p<0.01, N \geq 3$ for all strains tested. $\mathrm{AU}$, arbitrary units. 
A
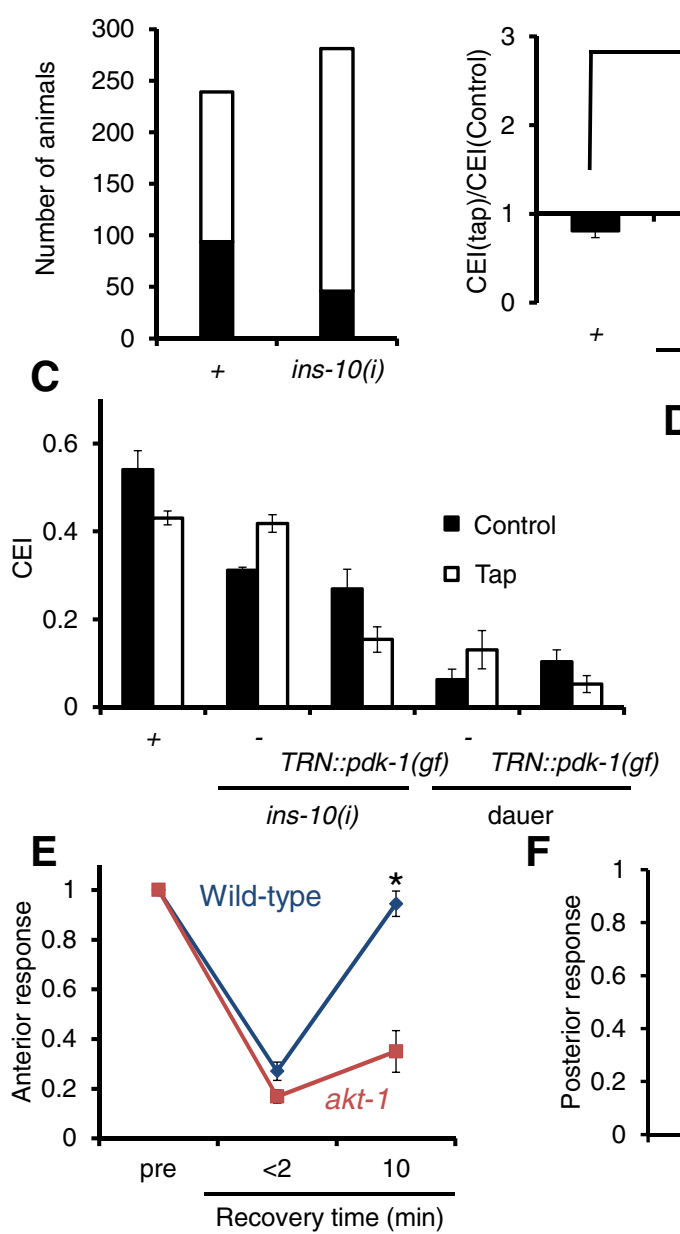

D

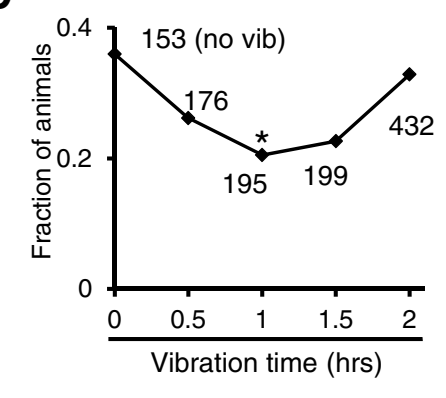

dauer

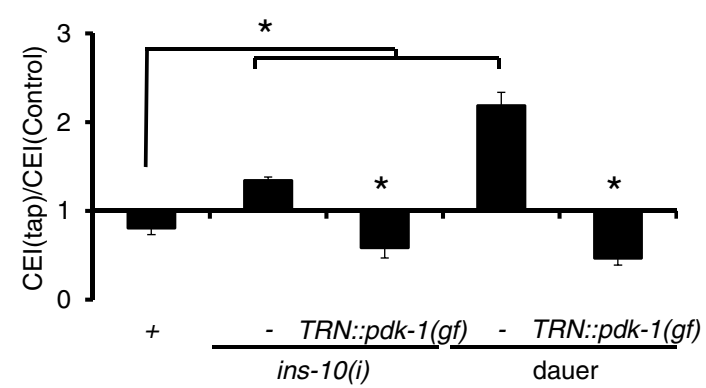

)

$F$

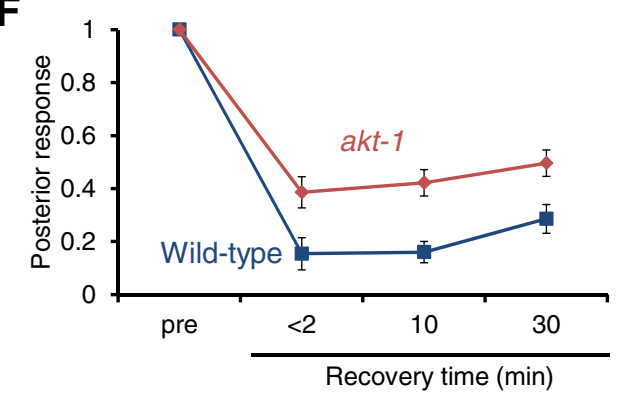

Figure 10. Behavioral consequences of mechanosensory modulation. $\boldsymbol{A}$, The number of animals responding to a pulse vibration by backward movement (black) or nonbackward movement (forward or no movement, white) in wild-type and ins-10( $i$ ) animals. The data are pooled from four independent trials; $p<0.0001$ comparing ins- $10(i)$ to wild-type. $\boldsymbol{B}$, The ratio of chemotaxis efficiency index (mean $\pm \mathrm{SEM}$; CEI, the fractions of animals that have reached the diacetyl spot) with or without tapping every $30 \mathrm{~s}$ during a 12 min chemotaxis assay; ${ }^{*} p<0.05$ comparing animals with or without TRN::pdk-1(gf), or comparing ins-10(i) or wild-type dauer with wild-type adults, $N \geq 3$ for all strains. C, The ratio of CEl (the fractions of animals that have reached the diacetyl spot; mean \pm SEM) with or without tapping. The data used are the same as in $\boldsymbol{B}$. $\boldsymbol{D}$, Fraction of animals moving backward in response to a $0.5 \mathrm{~s}$ vibratory pulse without sustained vibration (no vib) or with background sustained vibration for the indicated time. The total number of animals tested is noted at each point; ${ }^{*} p<0.01$ compared with no vib and $2 \mathrm{~h}$ using Fisher's exact test. $\boldsymbol{E}, \boldsymbol{F}$, Anterior $(\boldsymbol{E})$ and posterior $(\boldsymbol{F})$ response (mean \pm SEM) of wild-type (blue) or akt- 1 (red) animals to touch before habituation (pre) or after vibration for more than $2 \mathrm{~h}$ and rested for the indicated amount of time, normalized to the response before habituation; ${ }^{*} p<0.005$ comparing wild-type and $a k t-1$ responses, $N>10$ for all time points for each strain.

nel, but on a secondary mechanosensor involving integrins and other focal adhesion proteins to detect sustained stimuli. Longterm sensitization acts via a pathway that joins the insulin signaling pathway, which is affected by several stress signals. The joining of these pathways allows the integration of several different modulatory inputs into a single output. In addition, these various responses occur only in the anterior TRNs and not in the posterior cells. Kindt et al. (2007) also found a difference between the anterior and posterior cells with regard to short-term habituation. Together these results suggest that these very similar looking touch-sensing cells actually function quite differently.

\section{Integrins sensitize the anterior TRNs}

Integrins anchor cells to the ECM and serve as cellular mechanosensors. The activation of integrins by mechanical force induces diverse changes such as cell proliferation and differentiation
(Roca-Cusachs et al., 2012). Integrin signaling has been implicated in the function of mechanosensory cells. For example, rats exposed to strong auditory stimuli increased the expression of integrins in the cochlear sensory epithelium; this change correlated with a shift in hearing threshold (Cai et al., 2012). In addition, mechanical hyperalgesia, where normal touch elicits a painful response, is reduced by blocking integrin signaling (Dina et al., 2004). The role of integrin signaling, however, in neuronal mechanosensation is unclear in these examples.

Our results show that the integrins are needed for the long-term sensitization of the anterior TRNs. The initial detection of prolonged stimulation does not require the MEC-4 channel. Given their involvement in this sensitization and their actions in other cells, the integrins are prime candidates for the secondary mechanotransducer in the TRNs. This hypothesis does not exclude the possibility that integrins detect changes in the ECM caused by prolonged stimulation and thus act as a signaling molecule (indeed, change in ECM proteins usually accompanies or leads to integrin activation; Roca-Cusachs et al., 2012). Because integrins respond less quickly than the MEC-4 channels, they are more suited for detecting sustained stimuli. We propose that these two systems respond to different mechanical signals; the MEC- 4 channels are activated by changes in displacement, whereas the focal adhesions respond to sustained or repeated force. In addition MEC-4 channels do not require the him-4-dependent anchorage of the TRNs to the hypodermis to function, but the integrins and sensitization do.

\section{Sensitization counters habituation during sustained stimulation}

Similar sensitization is seen in mammalian hearing and mechanical nociception (Kujawa and Liberman, 1999; Govindaraju et al., 2006; Chen et al., 2010), suggesting that sensitization following sustained stimulation may be a conserved and common characteristic of mechanosensory systems. The counteracting effects of sensitization and habituation, both occurring after sustained stimuli, pose an intriguing dilemma: why would the animal reduce the behavioral response but concurrently become more sensitive to the stimulus? Our data suggest that sensitization allows animals to respond better during and after habituation.

Habituation attenuates the response to repeated stimulation. This process allows the animal to ignore background stimuli, but also reduces its sensitivity to specific stimuli, making the animal more vulnerable to predators (Maguire et al., 2011). Sensitized animals respond slightly better during background stimulation (Fig. 10D), but much better after the cessation of background stimulation (Fig. 10E). Therefore, sensitized animals could main- 


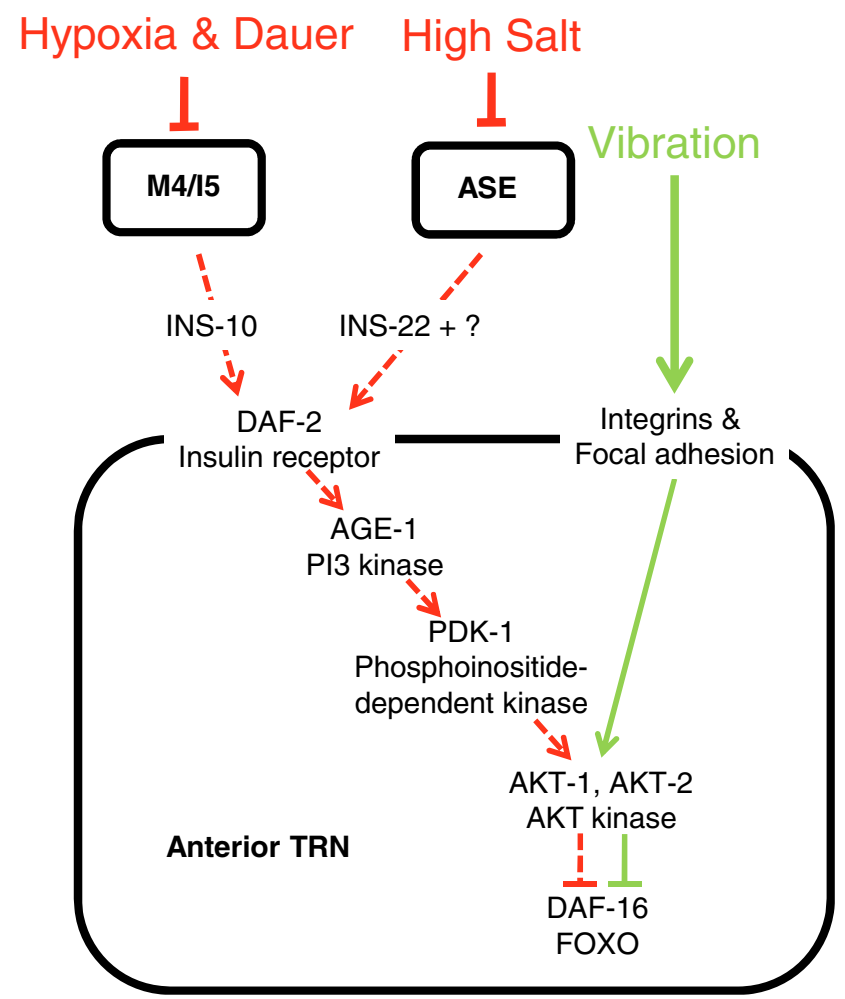

Figure 11. Regulation of TRN mechanosensation. Sustained vibration (green pathway) sensed by integrins, and hypoxia, dauer formation, and high salt (red pathway) sensed by insulin peptides, converge on AKT-1and DAF-16 to modulate touch sensitivity in the anterior TRNs. Dashed connectors indicate that the signaling strength is attenuated by the corresponding signals.

tain their defenses against predators in the face of sustained background stimulation. Because sensitization occurs over hours, but habituation can occur within minutes (Rankin et al., 1990), sensitization may be a further adaptation to prolonged habituation to reduce risks associated with attenuated touch response. Longterm sensitization, thus, could provide a strong survival advantage in the wild under conditions that might stimulate the animals mechanically for prolonged periods, such as rain, which is simulated by our $1 \mathrm{~Hz}$ stimulation experiment.

\section{Neurohormones coordinate senses under stress conditions}

Sensory modulation optimizes behavioral outcomes in many species (Sillar and Skorupski, 1986; Maney and Pinaud, 2011). These changes in sensory perception allow different behavioral responses depending on environmental cues. Here we show that stress conditions sensed by several other cells modulate C. elegans touch sensitivity through insulin-like neurohormones. If insulinbased regulation of touch sensitivity is more general, the loss of insulin signaling may underlie neuropathic numbness in humans, a common early symptom during prediabetic neuropathy (Vincent et al., 2011).

Mechanosensory responses are robust and faster than those of other senses, such as olfaction or thermal sensitivity; they, thus, take priority over other senses in determining an animal's behavior. Our data suggest, however, that this neuronal priority can be reordered through neurohormonal modulation. We saw, for example, that animals with reduced anterior touch sensitivity performed better when chemotaxing in the presence of mechanical distraction. Therefore, the reduction of touch sensitivity under stress conditions may facilitate escape from the stress environ- ment by lowering the priority of mechanosensation. Conversely, we imagine that under good conditions, increased touch sensitivity would prepare the animals for escape from mechanical signals in the face of favorable environmental signals that would otherwise have them remain in place. Previous studies by Kindt et al. (2007) on dopamine modulation of touch habituation also support this hypothesis.

Such a change in priority may be an important adaptive change in the wild. In particular, we find that dauer larvae actually accumulate more rapidly at a source of an attractive chemosensory signal when mechanical stimuli are present (Fig. 10D). Thus, in this instance mechanosensory signals can attract rather than repel, a reversal of the normal sensory behavior. Interestingly, Torr et al. (2004) found that infectious larvae (the equivalent to the $C$. elegans dauer larvae) from three different nematodes, Steinernema carpocapsae, S. feltiae, and Heterorhabditis megidis, which parasitize insects, were better able to find prey (greater wax moth larvae) when vibratory signals were present.

\section{The organization of sensory modulatory networks}

Although many sensory cells (Fex, 1967; Sillar and Skorupski, 1986; Massey and Redburn, 1987) receive synaptic inputs from efferent neurons, the TRNs receive no obvious synaptic inputs (Chalfie et al., 1985). Our data indicate, however, that a complex, nonsynaptic signaling network integrates multiple nonmechanical signals to modify the activity of the TRNs.

Modulatory signals from different neurons converge on the TRNs through different neuropeptides: the M4/I5 cells secrete INS-10, and the ASE cells rely on INS-22 and possibly other neuropeptides. The M4/I5 cells are pharyngeal interneuron/motor neurons that control pharyngeal pumping. These cells, however, also secrete multiple neuropeptides (Rogers et al., 2003) and receive neurohormonal inputs (Pocock and Hobert, 2010) from outside of the pharynx. These observations and our data suggest that the M4 and I5 neurons act as neurohormonal hubs that function similarly to interneurons in a synaptic network: they integrate information and modulate multiple downstream neurons through diverse neurohormonal peptides. These cells may constitute a primitive neuroendocrine system similar to the Drosophila pars intercerebralis and pars lateralis and the mammalian hypothalamus (Hartenstein, 2006), which also secrete neuropeptides and hormones to regulate animal behavior and development. Convergence of modulatory signals through neurohormonal hubs and at the TRNs through insulin signaling allows multiple non-mechanical stress conditions to regulate touch sensitivity through a common mechanism. This nonsynaptic network may potentially mediate modulation of touch sensitivity through additional neuropeptides, including the FLPs, NLPs, oxytocin/vasopressin-like neuropeptides, and other redundant or negatively acting insulin-like peptides.

Subsequently, the input of the insulin signals is integrated with that of integrin signaling, which respond to mechanical activation, by AKT-1 and AKT-2 in the TRNs. The AKT kinases then suppress the activity of DAF-16/FOXO transcription factor, which provides a common mechanism to integrate both mechanical and non-mechanical modulatory signals. The relatively slow rate of transcriptional regulation probably explains why all four conditions require several hours to affect touch sensitivity. This convergence allows compensation between conflicting modulatory signals from different modalities: the reduced touch sensitivity under non-mechanical stress conditions or in insulin signaling mutants can be restored by mechanical stimulation, and the reduced touch sensitivity caused by loss of integrin 
signaling can be compensated by increasing insulin signaling. Together, the signaling convergence on AKT kinases and the nonsynaptic networks unify multisensory cues at multiple levels to modify sensory perception through a common mechanism.

\section{References}

Albertson DG, Thomson JN (1976) The pharynx of Caenorhabditis elegans. Philos Trans R Soc Lond B Biol Sci 275:299-325. CrossRef Medline

Baum PD, Garriga G (1997) Neuronal migrations and axon fasciculation are disrupted in ina-1 integrin mutants. Neuron 19:51-62. CrossRef Medline

Bounoutas A, O'Hagan R, Chalfie M (2009) The multipurpose 15protofilament microtubules in C. elegans have specific roles in mechanosensation. Curr Biol 19:1362-1367. CrossRef Medline

Brenner S (1974) The genetics of Caenorhabditis elegans. Genetics 77:71-94. Medline

Cai Q, Patel M, Coling D, Hu BH (2012) Transcriptional changes in adhesion-related genes are site-specific during noise-induced cochlear pathogenesis. Neurobiol Dis 45:723-732. CrossRef Medline

Calixto A, Chelur D, Topalidou I, Chen X, Chalfie M (2010) Enhanced neuronal RNAi in C. elegans using SID-1. Nat Methods 7:554-559. CrossRef Medline

Chalfie M (2009) Neurosensory mechanotransduction. Nat Rev Mol Cell Biol 10:44-52. CrossRef Medline

Chalfie M, Sulston J (1981) Developmental genetics of the mechanosensory neurons of Caenorhabditis elegans. Dev Biol 82:358-370. CrossRef Medline

Chalfie M, Thomson JN (1982) Structural and functional diversity in the neuronal microtubules of Caenorhabditis elegans. J Cell Biol 93:15-23. CrossRef Medline

Chalfie M, Sulston JE, White JG, Southgate E, Thomson JN, Brenner S (1985) The neural circuit for touch sensitivity in Caenorhabditis elegans. J Neurosci 5:956-964. Medline

Chen X, Green PG, Levine JD (2010) Neuropathic pain-like alterations in muscle nociceptor function associated with vibration-induced muscle pain. Pain 151:460-466. CrossRef Medline

Connolly E, Braunstein S, Formenti S, Schneider RJ (2006) Hypoxia inhibits protein synthesis through a $4 \mathrm{E}-\mathrm{BP} 1$ and elongation factor 2 kinase pathway controlled by mTOR and uncoupled in breast cancer cells. Mol Cell Biol 26:3955-3965. CrossRef Medline

Croll NA (1975) Components and patterns in the behavior of the nematode Caenorhabditis elegans. J Zool 176:159-176.

Dalley BK, Golomb M (1992) Gene expression in the Caenorhabditis elegans dauer larva: developmental regulation of Hsp90 and other genes. Dev Biol 151:80-90. CrossRef Medline

Dina OA, Parada CA, Yeh J, Chen X, McCarter GC, Levine JD (2004) Integrin signaling in inflammatory and neuropathic pain in the rat. Eur J Neurosci 19:634-642. CrossRef Medline

Fain GL, Matthews HR, Cornwall MC, Koutalos Y (2001) Adaptation in vertebrate photoreceptors. Physiol Rev 81:117-151. Medline

Fex J (1967) Efferent inhibition in the cochlea related to hair-cell dc activity: study of postsynaptic activity of the crossed olivocochlear fibres in the cat. J Acoust Soc Am 41:666-675. CrossRef Medline

Gettner SN, Kenyon C, Reichardt LF (1995) Characterization of $\beta p a t-3$ heterodimers, a family of essential integrin receptors in C. elegans. J Cell Biol 129:1127-1141. CrossRef Medline

Govindaraju SR, Curry BD, Bain JL, Riley DA (2006) Comparison of continuous and intermittent vibration effects on rat-tail artery and nerve. Muscle Nerve 34:197-204. CrossRef Medline

Gravato-Nobre MJ, Nicholas HR, Nijland R, O'Rourke D, Whittington DE, Yook KJ, Hodgkin J (2005) Multiple genes affect sensitivity of Caenorhabditis elegans to the bacterial pathogen Microbacterium nematophilum. Genetics 171:1033-1045. CrossRef Medline

Hartenstein V (2006) The neuroendocrine system of invertebrates: a developmental and evolutionary perspective. J Endocrinol 190:555-570. CrossRef Medline

Hedgecock EM, Culotti JG, Hall DH, Stern BD (1987) Genetics of cell and axon migrations in Caenorhabditis elegans. Development 100:365-382. Medline

Hobert O, Moerman DG, Clark KA, Beckerle MC, Ruvkun G (1999) A conserved LIM protein that affects muscular adherens junction integrity and mechanosensory function in Caenorhabditis elegans. J Cell Biol 144:4557. CrossRef Medline

Hötting K, Rösler F, Röder B (2003) Crossmodal and intermodal attention modulate event-related brain potentials to tactile and auditory stimuli. Exp Brain Res 148:26-37. CrossRef Medline

Hristova M, Birse D, Hong Y, Ambros V (2005) The Caenorhabditis elegans heterochronic regulator LIN-14 is a novel transcription factor that controls the developmental timing of transcription from the insulin/insulinlike growth factor gene ins-33 by direct DNA binding. Mol Cell Biol 25:11059-11072. CrossRef Medline

Hu, PJ (2007) Dauer. In Wormbook (The C. elegans research community, ed). doi: 10.1895/wormbook. 1.144.1. http://www.wormbook.org.

Kim ME, Shrestha BR, Blazeski R, Mason CA, Grueber WB (2012) Integrins establish dendrite-substrate relationships that promote dendritic selfavoidance and patterning in drosophila sensory neurons. Neuron 73:7991. CrossRef Medline

Kindt KS, Quast KB, Giles AC, De S, Hendrey D, Nicastro I, Rankin CH, Schafer WR (2007) Dopamine mediates context-dependent modulation of sensory plasticity in C. elegans. Neuron 55:662-676. CrossRef Medline

Kujawa SG, Liberman MC (1999) Long-term sound conditioning enhances cochlear sensitivity. J Neurophysiol 82:863-873. Medline

Lin X, Qadota H, Moerman DG, Williams BD (2003) C. elegans PAT-6/ actopaxin plays a critical role in the assembly of integrin adhesion complexes in vivo. Curr Biol 13:922-932. CrossRef Medline

Littlewood Evans A, Müller U (2000) Stereocilia defects in the sensory hair cells of the inner ear in mice deficient in integrin $\alpha 8 \beta 1$. Nat Genet 24:424428. CrossRef Medline

Longo MR, Pernigo S, Haggard P (2011) Vision of the body modulates processing in primary somatosensory cortex. Neurosci Lett 489:159-163. CrossRef Medline

Mackinnon AC, Qadota H, Norman KR, Moerman DG, Williams BD (2002) C. elegans PAT-4/ILK functions as an adaptor protein within integrin adhesion complexes. Curr Biol 12:787-797. CrossRef Medline

Maguire SM, Clark CM, Nunnari J, Pirri JK, Alkema MJ (2011) The C. elegans touch response facilitates escape from predacious fungi. Curr Biol 21:1326-1330. CrossRef Medline

Maney DL, Maney D, Pinaud R (2011) Estradiol-dependent modulation of auditory processing and selectivity in songbirds. Front Neuroendocrinol 32:287-302. CrossRef Medline

Massey SC, Redburn DA (1987) Transmitter circuits in the vertebrate retina. Prog Neurobiol 28:55-96. CrossRef Medline

Nagel G, Brauner M, Liewald JF, Adeishvili N, Bamberg E, Gottschalk A (2005) Light activation of channelrhodopsin-2 in excitable cells of Caenorhabditis elegans triggers rapid behavioral responses. Curr Biol 15: 2279-2284. CrossRef Medline

O'Hagan R, Chalfie M, Goodman MB (2005) The MEC-4 DEG/ENaC channel of Caenorhabditis elegans touch receptor neurons transduces mechanical signals. Nat Neurosci 8:43-50. CrossRef Medline

Ortiz CO, Faumont S, Takayama J, Ahmed HK, Goldsmith AD, Pocock R, McCormick KE, Kunimoto H, Ino Y, Lockery S, Hobert O (2009) Lateralized gustatory behavior of C. elegans is controlled by specific receptortype guanylyl cyclases. Curr Biol 19:996-1004. CrossRef Medline

Palouzier-Paulignan B, Lacroix MC, Aimé P, Baly C, Caillol M, Congar P, Julliard AK, Tucker K, Fadool DA (2012) Olfaction under metabolic influences. Chem Senses 37:769-797. CrossRef Medline

Persad S, Attwell S, Gray V, Mawji N, Deng JT, Leung D, Yan J, Sanghera J, Walsh MP, Dedhar S (2001) Regulation of protein kinase B/Akt-serine 473 phosphorylation by integrin-linked kinase: critical roles for kinase activity and amino acids arginine 211 and serine 343 . J Biol Chem 276: 27462-27469. CrossRef Medline

Pierce SB, Costa M, Wisotzkey R, Devadhar S, Homburger SA, Buchman AR, Ferguson KC, Heller J, Platt DM, Pasquinelli AA, Liu LX, Doberstein SK, Ruvkun G (2001) Regulation of DAF-2 receptor signaling by human insulin and ins-1, a member of the unusually large and diverse C. elegans insulin gene family. Genes Dev 15:672-686. CrossRef Medline

Pinsker HM, Hening WA, Carew TJ, Kandel ER (1973) Long-term sensitization of a defensive withdrawal reflex in Aplysia. Science 182:1039-1042. CrossRef Medline

Pinsker H, Kupfermann I, Castellucci V, Kandel E (1970) Habituation and dishabituation of the gill-withdrawal reflex in Aplysia. Science 167:1740 1742. CrossRef Medline 
Pocock R, Hobert O (2010) Hypoxia activates a latent circuit for processing gustatory information in C. elegans. Nat Neurosci 13:610-614. CrossRef Medline

Rankin CH, Beck CD, Chiba CM (1990) Caenorhabditis elegans: a new model system for the study of learning and memory. Behav Brain Res 37:89-92. CrossRef Medline

Roca-Cusachs P, Iskratsch T, Sheetz MP (2012) Finding the weakest link: exploring integrin-mediated mechanical molecular pathways. J Cell Sci 125:3025-3038. CrossRef Medline

Rogers C, Reale V, Kim K, Chatwin H, Li C, Evans P, de Bono M (2003) Inhibition of Caenorhabditis elegans social feeding by FMRFamiderelated peptide activation of NPR-1. Nat Neurosci 6:1178-1185. CrossRef Medline

Sillar KT, Skorupski P (1986) Central input to primary afferent neurons in crayfish, Pacifastacus leniusculus, is correlated with rhythmic motor output of thoracic ganglia. J Neurophysiol 55:678-688. Medline

Suzuki H, Kerr R, Bianchi L, Frøkjaer-Jensen C, Slone D, Xue J, Gerstbrein B, Driscoll M, Schafer WR (2003) In vivo imaging of C. elegans mechanosensory neurons demonstrates a specific role for the MEC-4 channel in the process of gentle touch sensation. Neuron 39:1005-1017. CrossRef Medline

Suzuki Y, Han M (2006) Genetic redundancy masks diverse functions of the tumor suppressor gene PTEN during C. elegans development. Genes Dev 20:423-428. CrossRef Medline

Topalidou I, Chalfie M (2011) Shared gene expression in distinct neurons expressing common selector genes. Proc Natl Acad Sci U S A 108:1925819263. CrossRef Medline

Topalidou I, van Oudenaarden A, Chalfie M (2011) Caenorhabditis elegans aristaless/Arx gene alr-1 restricts variable gene expression. Proc Natl Acad Sci U S A 108:4063-4068. CrossRef Medline

Torr P, Heritage S, Wilson MJ (2004) Vibrations as a novel signal for host location by parasitic nematodes. Int J Parasitol 34:997-999. CrossRef Medline

Tsalik EL, Hobert O (2003) Functional mapping of neurons that control locomotory behavior in Caenorhabditis elegans. J Neurobiol 56:178-197. CrossRef Medline

Vincent AM, Callaghan BC, Smith AL, Feldman EL (2011) Diabetic neuropathy: cellular mechanisms as therapeutic targets. Nat Rev Neurol 7:573583. CrossRef Medline

Vogel BE, Hedgecock EM (2001) Hemicentin, a conserved extracellular member of the immunoglobulin superfamily, organizes epithelial and other cell attachments into oriented line-shaped junctions. Development 128:883-894. Medline

Vogel V, Sheetz MP (2009) Cell fate regulation by coupling mechanical cycles to biochemical signaling pathways. Curr Opin Cell Biol 21:38-46. CrossRef Medline

Weber BA (1970) Habituation and dishabituation of the averaged auditory evoked response. J Speech Hear Res 13:387-394. Medline

Zaidel-Bar R (2009) Evolution of complexity in the integrin adhesome. J Cell Biol 186:317-321. CrossRef Medline 